Review

\title{
Emerging Piezol signaling in inflammation and atherosclerosis; a potential therapeutic target
}

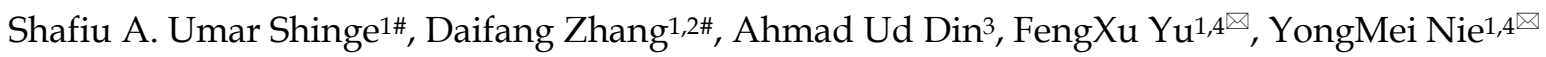 \\ 1. Cardiovascular Surgery Department, Affiliated Hospital of Southwest Medical University, Luzhou, Sichuan PRC. \\ 2. Clinical Research Center, Southwest Medical University, Luzhou, Sichuan PRC. \\ 3. Drug Discovery Research Center, Southwest Medical University, Luzhou, Sichuan PRC. \\ 4. Collaborative Innovation Center for Prevention and Treatment of Cardiovascular Disease of Sichuan Province, Southwest Medical University, Luzhou, Sichuan PRC. \\ \#These authors contributed equally to this work. \\ $\bowtie$ Corresponding authors: Tel; +86 13980259707, yuluchuan@163.com (F.Y), or nieyongmei@126.com (Y.N), +86 19938597025
}

(C) The author(s). This is an open access article distributed under the terms of the Creative Commons Attribution License (https://creativecommons.org/licenses/by/4.0/). See http://ivyspring.com/terms for full terms and conditions.

Received: 2021.08.18; Accepted: 2021.11.08; Published: 2022.01.01

\begin{abstract}
Purpose of Review: Atherosclerosis is the principal cause of cardiovascular diseases (CVDs) which are the major cause of death worldwide. Mechanical force plays an essential role in cardiovascular health and disease. To bring the awareness of mechanosensitive Piezol role in atherosclerosis and its therapeutic potentials we review recent literature to highlight its involvement in various mechanisms of the disease.

Recent Findings: Recent studies reported Piezol channel as a sensor, and transducer of various mechanical forces into biochemical signals, which affect various cellular activities such as proliferation, migration, apoptosis and vascular remodeling including immune/inflammatory mechanisms fundamental phenomenon in atherogenesis.

Summary: Numerous evidences suggest Piezol as a player in different mechanisms of cell biology, including immune/inflammatory and other cellular mechanisms correlated with atherosclerosis. This review discusses mechanistic insight about this matter and highlights the drugability and therapeutic potentials consistent with emerging functions Piezol in various mechanisms of atherosclerosis. Based on the recent works, we suggest Piezol as potential therapeutic target and a valid candidate for future research. Therefore, a deeper exploration of Piezol biology and translation towards the clinic will be a novel strategy for treating atherosclerosis and other CVDs.
\end{abstract}

Key words: Atherosclerosis; Piezo1 channel; Endothelial cell; Inflammation; shear stress; mechanomedicine

\section{Introduction}

Atherosclerosis is a chronic inflammatory disease [1-4], resulting from several factors [5]. It is the leading cause of fatality and morbidity globally [6,7]. Atherosclerosis is the multifactorial disease associated with various mechanisms such as inflammation, immune, and other cellular processes related to hyperlipidemia, obesity, diabetes, and associated metabolic disorders. Atherosclerosis prevalence is gradually increasing due to global increase in obesity and diabetes, leading to increase in cardiovascular diseases (CVDs) burden. As estimated, global death from CVDs may go beyond 23.6 million by the year 2030 [8]. The importance of mechanical forces in cardiovascular physiology and pathology have been reported for years. Endothelial cells (EC) sense mechanical force in the form of shear stress and transduce the force into biological signals through various membrane proteins $[9,10]$ including Piezo1. Various mechanical cues sensed by Piezo1 affect multiple signaling pathways, which lead to alterations in functions, phenotype, gene expressions and cell behavior including proliferation, migration, apoptosis and remodeling, the crucial features of atherosclerosis. It is increasingly clear from multiple clinical evidences and in vivo experimental subjects [9, 11] that mechanical force in form of low and oscillatory flow at the branching and curved vessel regions generates atherogenic shear, leading to EC inflammatory responses thereby developing distinct phenotype to distinctively interact with traditional 
risk factors and facilitate for the preferential site for vulnerability of atherosclerosis [12, 13]. In recent years, an outstanding multidisciplinary effort in research has led to an exciting discovery of novel mechanosensitive ion channels Piezo 1 \& 2, which bring us to a new era of mechano-transduction research. The channels are specialized with versatile functions of various mechanosensing, including stretching, membrane tension, cyclic pressure, shear stress and other mechanical cues. In addition to their identified functions, increasing evidence shows that their roles are not restricted to cardiovascular but in various aspects of cellular biology, including endothelial endocrine and paracrine aspects [14, 15]. Different abnormalities or up/downregulation of cellular activities were observed in several studies following the mutation, silencing/blocking, deletion, cell specific or global knockout and deficiency of Piezo1 [14, 16-22] based on its specific function. Due to Piezo1 physiological significance, its gain or loss-of-functioning mutants was found to correlate with various diseases in humans, including hereditary stomatocytosis [23] and generalized lymphatic dysplasia [24-26] indicating Piezo1 functional significance and its therapeutic potentials.

\section{Piezo discovery}

Mechanotransduction is the translation of mechanical forces into biochemical signals, which is necessary for potent cellular physiology. The molecular identity of mammalian mechanosensitive channels remained poorly understood, until the evolutionary discovery of Piezo channel family, which shed light on this mystery [27, 28]. This opens the door for more concepts on the distinctive molecular identities of these channels and mechanotransduction mechanisms for sensory signaling. Patapoutian team revealed in 2010 that Piezo1 and Piezo2 proteins, encoded by the Piezo1/ FAM38A and Piezo2/FAM38B genes, and recognized as mechanically activated (MA) cation channels, which are necessary in mammalian cell physiology. Piezo proteins are evolutionary conserved cellular mechanosensors that are necessary for proper multicellular physiology [29]. They were first recognized as potential channels in the neuroblastoma cell line (Neuro2A) through electrophysiology, combining whole cell stimulation/recording patch clamp, and molecular biology. Multiple cell types were mechanically stimulated by Coste et al. seeking for a cell line with a robust and repeatable mechano-responsiveness and he discovered it in Neuro2A. the authors examined approximately 75 genes and found one named Fam38A as important. The protein has about 2500 amino acids long and exhibits no similarity to other channels and was called Piezo1. Cloning of a homologues gene (named Piezo2) from cell of dorsal root ganglion (DRG) and searching of the databases indicated that there were homologues genes in numerous animals as well as plants $[29,30]$. Piezo2 currents were comparable to Piezo1 but it had significantly differential kinetics as well as conductance; with faster inactivation and a low unitary conductance and low level of expressions. Using quantitative PCR, the researcher found that RNA coding for Piezos concentrations differs in bladder, lung and skin with extremely high amounts of Piezo1. Whereas significant expression of Piezo2 was found in DRG neurons [31]. When piezo proteins are exposed to mechanical force, including shear stress, swelling, tension and compression, they release cations, which then promote cellular excitations and transmission of signals. Piezo1 is engaged in a variety of essential biological processes, including vascular [32] and lymphatic valve development [33, 34], blood pressure regulation, $\mathrm{RBC}$ volume regulation, bladder endothelial cell and renal tubular epithelial cell force sensing, and bone formation [14, 29]. In mammals, Piezo2 mediates the mechanotransduction process in somatosensation of pain, touch and proprioception [35]. Piezo1 and Piezo2 are substantially expressed in several mechanosensitive tissues in mouse. For instance, Piezo1 is abundant in mechanosensitive cells in the, bladder, skin, lung, kidney, and colon, while Piezo2 exhibits high expression in dorsal root ganglia primary sensory neurons, and in the lung, colon and bladder [29, 36]. The relevance of EC Piezo1 in vasculature biology was initially identified in recent study, and constitutive Piezo1 knockout (KO) was embryonically fatal in few days due to obvious deformity in developing vessels in mouse [37, 38]. However, Piezo2 was demonstrated necessary for mechanotransduction in Merkel cells, Piezo2 disrupting in the skin, exhibits decreased static firing ratio in mouse and reduced behavioral response to gentle touch stimuli [39]. Thus, authentically proving that Piezos serves physiological function for in vivo mechanosensing. Following their discovery, a number of studies were conducted on Piezo proteins architecture, their, cellular distribution in mammals, physiological functions and associated pathologies, and molecular mechanisms were demonstrated [40, 41] as discussed in this review. Convincingly, these findings proved that Piezo 1 and Piezo2 are genealogical products correlated with cellular mechanosensation.

\section{Piezo structure}

Piezo is the family of genes, Piezo1 and Piezo2, and are large transmembrane proteins that represent a 
special class of mechanically activated (MA) cation channels. Human (MA) channel molecular identity was mysterious for long, until the revolutionary discovery of Piezo 1\& 2, which may increase our understanding of cell signaling and mechanotransduction, bringing new opportunities for understanding and targeting theses signaling mechanisms involved in health and disease. Piezo1 protein identical to that of humans was initially discovered in a mouse. Piezo1 proteins are collectively arranged to form a three blade-like propeller, it is inserted within the lipid bilayer which makes the central ion pore that senses mechanical forces [42-45]. Piezo1 extracellular propeller domain serves as a sensor of flow related-shear and other mechanical stress [46, 47]. As observed on the cryo-electron microscope, several features of the channel morphology of mouse Piezo1, which is identical to that of humans, were identified. In respect to structure and function, Zhao et al. classified Piezo1 into three functional segments; (1) the ion-conduction pore portion which is C-terminal (2) the anchor; CTD, and the beam, which are the transducing elements, and (3) the TM blade-constituting mechanosensory portion [48], the structure of the channel are also deeply reviewed in the following pieces of literature [43, 45, 49]. It was earlier disclosed by various structural and functional studies that Piezo1 channel plays a versatile functions and demonstrated its association with other membrane proteins such as PECAM (platelet endothelial cell adhesion molecule) [14] ECM (extracellular matrix) FAZ (focal adhesion zones) AJs (adherence junctions) and cytoskeletal structures [27] etc., the Piezo1 interplay with cytoskeleton in mechano-sensing was comprehensively reviewed in detail by Nourse et al [27, 50], and for broad structural concept in recent paper [49]. Currently almost all of our understanding of the structure-function correlation of Piezo channels came from Piezo1 studies, while Piezo2 studies are so limited. However, the structure of full-length 2,822-residues of mice Piezo2 homo-trimers was determined to a resolution of 3.6-3.8, disclosing a totally resolved topography of 38 transmembrane helixes as well as a completely closed pore containing both transmembranous and cytosolic constriction regions. The enhanced Piezo2 specimen, which was solubilized in the detergent glycol-diosgenin (GDN), enabled the first acquiring of an overall 3.8-resolution cryo-electron microscope (cryo-EM) architecture that resembled the Piezo1 three-bladed, propeller-shaped architecture. All of the structural subunits seen in Piezo1 were resolved to 3.0 to 3.5 resolutions in the structure of Piezo2, with the exceptions of the extracellular cap (which was almost unresolved). In comparison to Piezo2, the Piezo1 cap domain rotates clockwise [51]. The outer part of the inner and outer helices, and the top transmembrane gates of Piezo1, display a clear outward extension in a clockwise manner related to Piezo2, but the adjacent TM25TM36 display a more modest and anticlockwise motions. When only the inner helix and the subsequent C-terminal subunit were overlaid, similar alterations in the inner helix and upper transmembrane gate were detected. Piezo1's outer part of the inner helix shows an outward extension of approximately a helical width (about 5.3) in comparison to Piezo2 [51, 52]. These alterations cause the top gate radius to increase from 0.9 for L2743 in Piezo2 to 4.5 for L2469 in Piezo1. Furthermore, when compared to Piezo2, the cap, beam subunits, and distal blade of the three Piezo1 structures are clearly displaced. Remarkably, the transmembrane gate - but not the cytosolic constriction neck - is dilated in all three Piezo1 structures, demonstrating that the differences in transmembrane pore conformation between the Piezo1 and Piezo2 structures are unlikely to be driven by detergent differences. Indeed, among the three Piezo1 structures, dilatation of the top transmembrane gate L2469 is strongly linked to cap domain displacement $[49,51]$.

\subsection{Piezo channels structure-function relationship}

As widely expressed in various cell types including cardiomyocytes, EC, VSMCs, and immune cells, Piezo1 play a wide range of roles in cellular physiology as well as pathology. Regarding this, researchers were curious in exploring the structures and/or domain of the channel involves in its function in health and disease. Despite revelation of general structure of Piezo1 by cryo-electron microscope (cryo-EM), the exact structural regions/subunits involved in activating as well as consequent inactivating of Piezo1 in correlation with its function are to be clarified. Through electrophysiology various researches study the possible structural domains to explore Piezo1 activation [53] and Piezo1\&2 inactivation kinetics amid mechanical stimulation [54]. Beside several structural studies [44, 55], Lewis et al revealed three tiny structural subunits in the extracellular cap, which could independently confer the distinctive kinetics of Piezo2 inactivating over Piezo1. Through cysteine crosslink the author demonstrated that conformational flexibilities of these subunits are required for mechanical activating to happen and that electrostatic interacting functionally copulate the cap to the extensive blades that was suggested to serve as sensors of membrane curvature as well as tensions. Both Piezo1 and Piezo2 mutating 
was found in patients diagnosed with distal arthrogryposis and xerocytosis $[16,56]$ that induces a gain-of-function mutants through delaying the inactivating, demonstrating that normal functions require perfect inactivation of the channel involving these subunits [54]. On the other hand, activation Piezo1 activation was demonstrated to involves concerted movements of the, outer helix, inner helix, anchor subunit, CTD, latch and beam subunits. Recent studies demonstrated that E2133 mutating influence single channel conducting as well as ion selectiveness, and sensitivity to the pore blocking agent ruthenium red [57]. In human Piezo1, the similar mutating of $\mathrm{R} 2482 \mathrm{H}$ leads to delayed inactivating kinetics and is correlated with dehydrated hereditary stomatocytosis $[23,58,59]$. These data imply that the anchor subunitinner helixes interacting in controlling the Piezo1 opening as well pore characteristics. Interestingly, human subject with dehydrated hereditary stomatocytosis have the similar mutants in R1353P, which could probably disrupt or kink the helical beam at this location and lead to slowing inactivating kinetics. Hence, the distal beam ending might be a structural determinant of gating features, potentially via interacting with the CTD [59]. These structures of Piezo1 present the high- resolution image of structural and functional relationship of this unique ion channel. The common human disorder of Piezo1 and Piezo2 gain of function mutating could be mapped into the structures, demonstrating that these models cover multiple of the functionally essential subunits and, furthermore, provides for a structural interpreting of the disease causative processes.

\subsection{Piezol activation and inactivation mechanisms}

Previous studies demonstrated Piezo1 activation mechanisms as in the concept of "Force-from-lipids" $[60,61]$, showing the force sensing mechanism of Piezo1 via the bilayer and unequivocal cytoskeletal engagement, including ECM. But the precise activation mechanism and how Piezo1 sense and transduce mechanical forces including the molecular and conformational alterations during the process is yet unknown. Using the advantages of recent advancement of structural and functional studies using cryo-electron microscope [51, 59], patch clamp electrophysiology $[62,63]$ and atomic force microscope [64] has brought invaluable awareness to the structure, functions and conformational alterations of Piezo1 channel in relation to its activation mechanisms. In these studies, various structures that contains the Piezo1 core site (Table 2) was lately disclosed [43, 63] and suggested their importance in the channel activation mechanisms by different mechanical, and chemical stimuli [50] (Table $3)$, as well as voltage gating [65], in association with other proteins, such as extracellular matrix (ECM) [66] and cytoskeletal structure [27], including two proposed mechanisms referred as "force-from-lipids" $[45,67]$ and "force-from-filaments"[50]. Shear stress considerably elevate membrane tension through augmenting membrane fluidity that encourages the phospholipid molecule activity, results in larger membrane tension [68], and membrane tension was reported to triggered Piezo1 with great intensity at 1.4 $\mathrm{mN} / \mathrm{m}[69,70]$. Recent study disclosed the possible mechanism and structural alteration which occurs upon mechanical gating of Piezo1, the study reported that in the absence of tensions, the curvaceous form of Piezo1 is balanced in an innate-analogue model membrane, producing indented membrane with trilobal topography. While Piezo1 flattens and expands its propeller domain for adopting stretched bilayer amid stretch application, leading to alteration in the beam helix tilting angle. Those activities lead to tilt and lateral motion of the pore lining of TM37 and TM38 helices, result in the gating of the channel and moving of lipid which occupies outer area of Piezo1 pore domain. The author further revealed that the Piezo1 structural flattening recognized by their work discloses C-terminal extracellular domain (CED) likely by shear stress, which was enclosed in the membrane before channel opening [71], demonstrating the mechanosensing and gating mechanism of Piezo1 channel including shear detection. Furthermore, Shi et al demonstrated the inhibition of PIEZO1 channel inactivation by sphingomyelinase (SMPD3) through accelerating the generation of ceramides (an important SMPD3 product), which favors the activating state of the channel over closed state like inactivating states. The author revealed that neutral sphingomyelinase antagonists as well as sphingomyelin phosphodiesterase 3 (SMPD3) genealogical interruption induces Piezo1 transition into a highly inactivating state. He further shows that ceramide also restores non-inactivating channel functions. Sphingomyelin (substrates of SMPD3), unlike ceramide, does not influence inactivation but does influence channel force sensitivities. Sphingomyelin (substrates of SMPD3), unlike ceramide, does not influence inactivation but does influence channel force sensitivities. This indicated sphingomyelinase activities, ceramide, and sphingomyelin as regulators of native Piezo gating, which permits prolong activities [72]. In addition to these outstanding findings, Scheuring and colleagues demonstrated that Piezo1 is a springy structure that normally bends the cellular membrane where it lies, but will flatten out 
when for instance a mechanical force is applied to the cell membrane. "As the membrane tension increases, the structure of Piezo1 flattens and stretches out to occupy a larger space, which in turn gates the ion channel", as stated by Scheuring. He also realized that other stimulus stretches and flattens Piezo1 structure, like that of a pulling force on its arms from internal or on outer domain (CED) from outer side of the cell, in principle can gate the channel, making it an appropriately adoptable mechanism for various cell types and physiological roles to which it operates [73]. Scheuring et al. also reported in Nature that, cryo-electron microscope showed that, in lipid vesicles of various sizes Piezo1 adapts distinct degrees of curvature [64]. Altogether these results demonstrate a great achievement and step forward toward elucidating the precise gating mechanism of Piezo1 and its integral structure for internal gating motions involved in Piezo1 mechanotransduction.

\section{Piezo1 functions}

Piezo1 was reported to function in sensing and transducing of various mechanical forces, such as membrane tension, stretching [29] including shear stress [37], cyclical pressure [75] etc. To bring awareness of its validity as therapeutic targets, we highlight its various roles and mainly focus on cardiovascular including immune/inflammatory cells summarized in (Table 1) and illustrated in (Figures 1 \& 2). Piezo1 is believed to have important roles in cardiovascular system. Increasing evidences revealed Piezo1 as cardinal player in the development, sustenance and normal function of the vasculature, inclusive of determining vessel architecture in embryonic and adult physiology. It also plays various roles in endothelium, including eNOS phosphorylation and vascular endothelial protein tyrosine phosphatase (VE-PTP) mediated endothelial

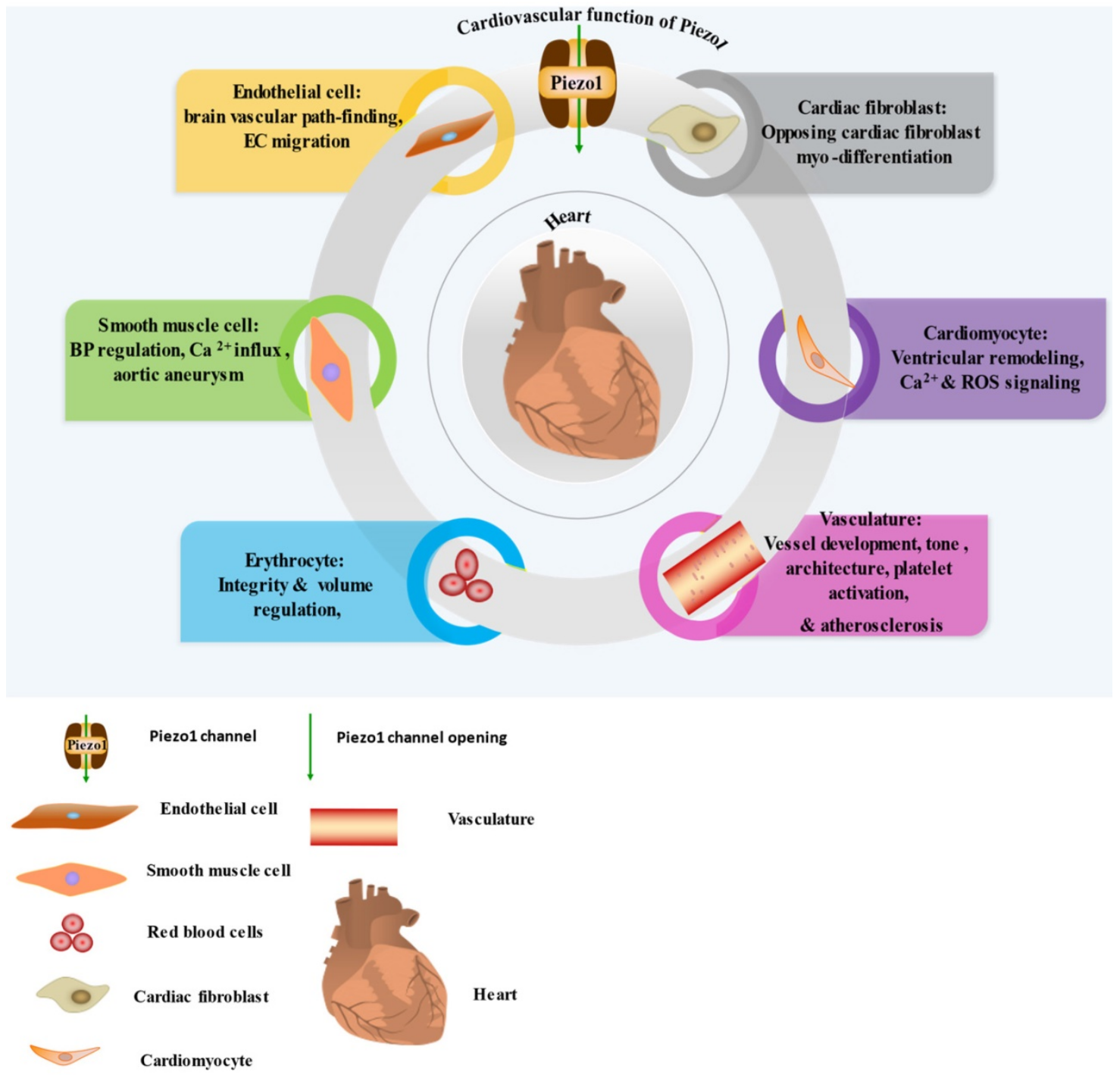

Figure 1. Cardiovascular expression and function of Piezol, the detail Piezol role in each cell and tissue shown here explains in the main text of the review. In the diagram I-VI illustrating the significant functions of Piezol in EC, SMC, RBC, cardiomyocyte, cardiac fibroblast and vasculature. 
dysfunction and hypertension in diabetes [76], contributing to the development and progression of atherosclerosis. Piezo1 is also player in cardiac fibroblast mechanotransduction, such as in fibrotic remodeling of heart, cell proliferation, differentiation of myofibroblasts, extracellular matrix turnover as well as paracrine signals [77]. In mice, extensive interruption of the sprouting vessel and embryonic lethality was observed few days after heart begin to beats following its universal or endothelial specific disrupting [14, 78, 79]. It is also necessary for outflow tracts as well as the formation of aortic valves [80]. Piezo1 was also found to be significant in the regulation of lymphatic valve formation. Study by Nonomura and colleagues, using mice deficient of Piezo1 displayed decreased quantity of lymphatic valves, indicating the relevance of Piezo1 in lymphatic system [33]. Another study in patient of familial lymphatic abnormality demonstrates the necessity of Piezo1 for normal functioning of lymphatic system. Compound heterozygous and homozygous mutants of Piezo1 were discovered in individuals with chronic lymphedema, ascites and pleural effusion related to inherited lymphatic dysplasia [24, 81]. Piezo1 global knockout in mice leads to embryonic fatality [24, 38, $46,82,83]$, demonstrating the necessity of Piezo1 during embryogenesis. Piezo1 was also recently reported to functions in skeletal muscles regeneration by boosting the functioning of satellite cells [84]. Additionally, severe defects in vessel maturation and remodeling, and disability in $\mathrm{NO}$ production and vessel dilation responding to flow was both observed following Piezo1 universal deletion or EC-specific disruption [37, 79]. Piezo1 was reported to have versatile functions and it is responsible for detection and transduction of flow shear as discussed in Section 4, cell proliferation and migration in Section 5.3, immune cells activation and cytokine release in Section 5.2, in inflammation and atherosclerosis in Section $5.1 \&$ 5.2. For review check ref. [14, 27, 40, 45, 85]. Altogether these functions demonstrate Piezo1 potentiality as promising target for novel therapeutic innovation against atherosclerosis and other CVDs.

Table 1. Summarizing the cardiovascular and immune functions of Piezol

\begin{tabular}{|c|c|c|c|c|c|c|c|}
\hline $\begin{array}{l}\text { Organ/ } \\
\text { Tissue }\end{array}$ & Functions & Associated disorder & $\begin{array}{l}\text { Human/animal; } \\
\text { mutation/genetic } \\
\text { disruption, inhibition } \\
\text { or Up-regulation/ } \\
\text { Downregulation }\end{array}$ & Cell type & Interactions & Downstream mechanisms & References \\
\hline \multirow[t]{3}{*}{ Heart } & Ventricular remodeling & Heart failure & Human; upregulation & $\begin{array}{l}\text { Cardio- } \\
\text { myocytes }\end{array}$ & $\begin{array}{l}\text { Hemodynamic/ } \\
\text { mechanical force, } \\
\text { shear stress, }\end{array}$ & $\begin{array}{l}\text { AngII dependent deterioration } \\
\text { of failing heart }\end{array}$ & [155] \\
\hline & $\mathrm{Ca}^{2+} \&$ ROS signaling & Cardiomyopathy & $\mathrm{mKO}$ & $\begin{array}{l}\text { Cardio- } \\
\text { myocytes }\end{array}$ & $\begin{array}{l}\text { Hemodynamic/ } \\
\text { mechanical force, } \\
\text { shear stress }\end{array}$ & Cardiac $\mathrm{Ca}^{2+}$ homeostasis & [156] \\
\hline & $\begin{array}{l}\text { Opposing cardiac fibroblast } \\
\text { myo-differentiating }\end{array}$ & NR & NE & $\begin{array}{l}\text { Cardiac } \\
\text { fibroblast }\end{array}$ & Pressure & IL-6 secreting & [157] \\
\hline \multirow[t]{6}{*}{$\begin{array}{l}\text { Blood/ } \\
\text { Lymph } \\
\text { Vessels }\end{array}$} & $\begin{array}{l}\text { Hypertension-dependent } \\
\text { remodeling of artery, BP } \\
\text { regulation, } \mathrm{Ca}^{2+} \text { influx \& ECM } \\
\text { degradation in AAA }\end{array}$ & $\begin{array}{l}\text { Arterial remodeling, } \\
\text { Abdominal aortic } \\
\text { aneurism }\end{array}$ & mcKO & SMCs & $\begin{array}{l}\text { Hemodynamic } \\
\text { force, shear stress, } \\
\text { mechanical } \\
\text { stretching }\end{array}$ & $\begin{array}{l}\text { Rise in transglutaminase } 2 \\
\text { activities }\end{array}$ & $\begin{array}{l}{[14,27,45,} \\
110,158]\end{array}$ \\
\hline & $\begin{array}{l}\text { Brain vascular pathfinding, } \\
\text { vascular growth, vessel tone \& } \\
\text { remodeling, Control of placental } \\
\text { blood flow, EC migration; Vessel } \\
\text { architecture; Hyperpermeability } \\
\text { of Pulmonary micro vessels }\end{array}$ & $\begin{array}{l}\text { Atherosclerosis, } \\
\text { Hypertension, } \\
\text { Pericardial effusion }\end{array}$ & $\begin{array}{l}\text { mcKO, Upregulation/ } \\
\text { dowmregulation }\end{array}$ & VECs & $\begin{array}{l}\text { Hemodynamic } \\
\text { force, shear stress, } \\
\text { Cyclic pressure }\end{array}$ & $\begin{array}{l}\text { Trigger of eNOS, AKT, KLF2, } \\
\text { VEGFR2 \& tyrosine } \\
\text { phosphorylating, P2Y2 } \\
\text { (purinergic receptor type 2Y2) } \\
\text { receptor activation }\end{array}$ & {$[14,159]$} \\
\hline & $\begin{array}{l}\text { Lymphatic valves development } \\
\text { \& sustenance }\end{array}$ & $\begin{array}{l}\text { Generalized lymphatic } \\
\text { dysplasia }\end{array}$ & mcKO (LFm humans) & LECs & $\begin{array}{l}\text { Hemodynamic } \\
\text { force, shear stress, } \\
\text { cyclic stretch }\end{array}$ & $\begin{array}{l}\text { actomyosin \& VE-cadherin } \\
\text { remodeling }\end{array}$ & {$[14,33,45]$} \\
\hline & $\begin{array}{l}\text { RBC Volume regulation, release } \\
\text { of ATP }\end{array}$ & $\begin{array}{l}\text { DHS and Plasmodium } \\
\text { infection, Hemolytic } \\
\text { anemia }\end{array}$ & GFm humans, cKd & RBC & $\begin{array}{l}\text { Hemodynamic } \\
\text { force, shear stress }\end{array}$ & $\begin{array}{l}\text { Elevated cation permeability } \\
\text { leading to dehydrating of } \\
\text { erythrocyte }\end{array}$ & {$[23,160]$} \\
\hline & $\begin{array}{l}\text { Shear-evoked influx of Ca2+, } \\
\text { Platelet activation \& } \\
\text { thrombogenesis }\end{array}$ & NR & NE & Platelets & Shear stress & Not clear & $\begin{array}{l}{[45,161,} \\
162]\end{array}$ \\
\hline & Baroreceptor reflex & $\begin{array}{l}\text { Baroreflex } \\
\text { dysfunctioning }\end{array}$ & $\begin{array}{l}\mathrm{mKO} / \text { mutant } \\
\text { Piezo1\&2 }\end{array}$ & $\begin{array}{l}\text { nodose \& } \\
\text { petrosa } \\
\text { sensory cells }\end{array}$ & $\begin{array}{l}\text { Hemodynamic } \\
\text { force, shear stress, }\end{array}$ & Raise in mean arterial pressure & {$[14,163]$} \\
\hline \multirow[t]{2}{*}{$\begin{array}{l}\text { Immune } \\
\text { system }\end{array}$} & $\begin{array}{l}\text { Prevent against P.aeruginosa, } \\
\text { generation of EDN1 and HIF1a }\end{array}$ & $\begin{array}{l}\text { Dysfunctional } \\
\text { immunity against } P \text {. } \\
\text { aeruginosa }\end{array}$ & mcKO/ inhibition & $\begin{array}{l}\text { Monocyte/ } \\
\text { Macrophage }\end{array}$ & Cyclic pressure & $\begin{array}{l}\text { Neutrophil recruiting and } \\
\text { clearing of pathogens }\end{array}$ & $\begin{array}{l}{[75,103,} \\
104]\end{array}$ \\
\hline & $\begin{array}{l}\text { Influx of } \mathrm{Ca}^{2+} \text { and TCR } \\
\text { stimulation }\end{array}$ & Unknown & $\begin{array}{l}\text { Downregulation/ } \\
\text { inhibition }\end{array}$ & T-cells & $\begin{array}{l}\text { Mechanical force/ } \\
\text { pressure }\end{array}$ & $\begin{array}{l}\text { Calpain trigger, actin scaffold } \\
\text { reorganizing, and stabilizing } \\
\text { immunological synapse }\end{array}$ & {$[93,164]$} \\
\hline
\end{tabular}

Abbreviations: TCR; T cell antigen receptor, GLD; generalized lymphatic dysplasia, ECM; extracellular matrix, mcKO; mice conditional knockout, NE; not explored, BP; blood pressure; DHS; dehydrated hereditary stomatocytosis; GFm, gain-of-function mutant, cKd; conditional knockdown, NR; not reported, AAA; Abdominal aortic aneurysm. 


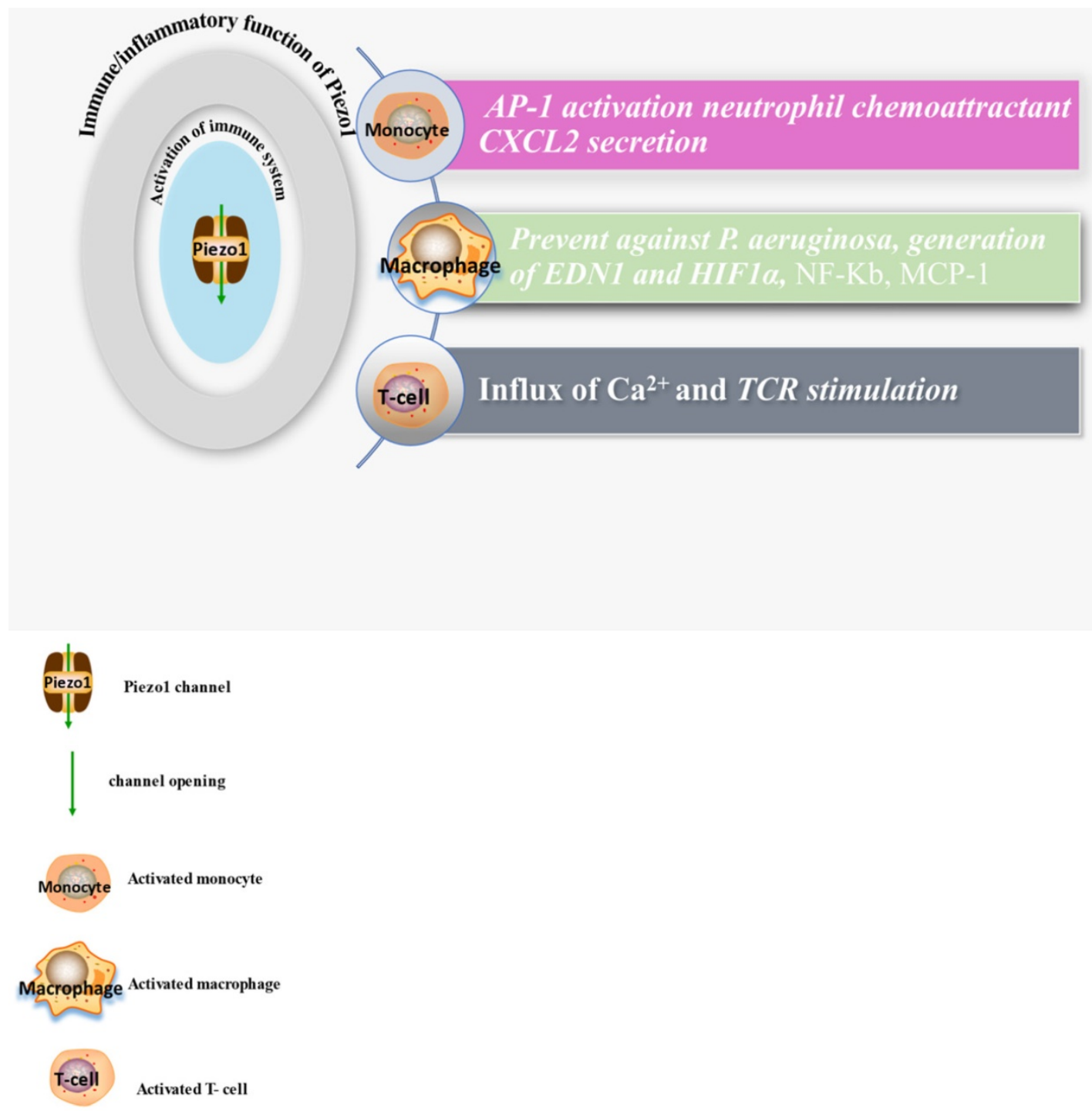

Figure 2. The diagram displays expressions and functions of Piezol in immune cells, comprising monocyte, macrophage and T-cells, illustrating the activities of these cell and secretion of chemokines after Piezol dependent activation as discussed in the main text of this work.

Table 2. Demonstrated activation and inactivation sites of Piezol

\begin{tabular}{|c|c|c|c|}
\hline \multicolumn{2}{|l|}{ Mechanical } & \multicolumn{2}{|l|}{ Chemical } \\
\hline Activation & Inactivation & Activation & Inactivation \\
\hline Sites/subdomain & & & \\
\hline $\begin{array}{l}\text { N-terminal proximity } \\
86 \& 300 \text { sites [63] ELs } \\
\text { of distal THU4 \& } \\
\text { THU5 [45] }\end{array}$ & $\begin{array}{l}\text { External pore } \\
\text { domain sites } \\
2,422 \& 2,425 \\
{[63]}\end{array}$ & $\begin{array}{l}\text { EL15-16, EL19-20 } \\
\& \text { L1342/L1345 at } \\
\text { the beam }[45,74]\end{array}$ & $\begin{array}{l}\text { L2475 \& V2476 } \\
\text { Residues [45, 74] }\end{array}$ \\
\hline
\end{tabular}

\subsection{Piezol shear stress sensing}

Shear stress resulting from blood flow is important phenomenon and vital for cardiovascular physiology. Piezo1 is well recognized and specialized shear stress sensor as proved by many evidences. Regardless of Piezo1 research infancy, the physiological and pathological relevance of Piezo1 in various aspects of cardiovascular was earlier reported $[14,86,87]$. Piezo1 play significant roles in multiple aspects of cardiovascular including embryonic vessel development and regulating of brain vascular pathfinding discussed earlier, and its mutants were correlated with various disorders in human. It was reported that, embryonic vessel development which is believed to be evoked by shear stress was interrupted following the knockdown of Piezo1 [14]. In the study by Rode and colleagues, rapid activation of endogenous Piezo1 channel by shear stress was observed in excised membrane patch recordings from endothelial cell. Flow-induced depolarization of -43 $\mathrm{mV}$ resting membrane potential, recorded in membrane patches from endothelial fragment was found to be diminished and hyperpolarized, after conditional deletion of endothelial Piezo1 [32, 62]. However, shear stress phenomenon in ex vivo experiment was found to be restrained or absent after endothelial Piezo1 knockdown. These findings proved Piezo1 as bona fide shear sensor and it is required for transducing shear forces into biochemical 
signals. Despite its recognition as shear sensor and backed by bountiful evidences, we still have a fundamental question of what is the precise mechanism of Piezo1 shear sensing and what are the exact structures and domain involved in Piezo1 activation by shear stress, other mechanical and chemical stimulus? This is of course a critical and difficult question to address due to the technical limitations and infancy of Piezo research. Several studies disclosed lately, the mechanism and domains that may be involved in the modulation of channel activation and inactivation of the channel as discussed in Section 5.

\subsection{Association of Piezol signaling with inflammation and atherosclerosis}

Atherosclerosis is a multifactorial and complex disease process of the vasculature involving various mechanisms and pathways in its pathogenesis. Accumulating evidences suggested the role of immune/inflammatory and other cellular process like cell proliferation, migration, apoptosis and remodeling in atherosclerotic pathogenesis [88-92] (Figures 3 \& 4), and Piezo1 was reported to play crucial roles in aforementioned cellular activities. In this regard, it is considered pivotal for the integration of various pathways driving atherosclerosis pathogenesis and complications. Mechanosensitive Piezo1 channel play multiple roles in various aspects of cardiovascular including health and disease. Recent studies reported the involvement of Piezo1 in inflammation and immunity (discussed in Section 6.1), and cellular activities such as proliferation and migration (discussed in Section 6.2) and activation of proinflammatory mediators such as cytokine release, thus, coupling both traditional and other emerging risks to atherosclerosis.

\subsection{Piezol mediated mechanical signals in inflammation and atherosclerosis}

It is now appreciated that several inflammatory/ immune mechanisms are involved in atherosclerosis. Inflammatory/immune cells such as monocytes and macrophages respond to mechanical stress via Piezo1 and display proinflammatory gene expression. Recent studies revealed the crucial role of Piezo1 in activation of T cell [93], NLRP3 inflammasome and assembling [94]. Solis et al. unveiled the sensing ability of Piezo1 to cyclical pressure that triggers proinflammatory activities in immune/inflammatory cells (myeloid cells). In his effort to explore the effect of mechanical force on immune/inflammatory cells, he exposes immune/inflammatory cells to pressure cycle alteration in vitro, and found increased Piezo1dependent cyclical hydrostatic pressure evokes proinflammatory gene expression in control, compare to Piezo1 disrupted cells. Furthermore, application of mechanical force to monocytes and macrophage initiates robust and specific pattern of Piezo1dependent expression of proinflammatory and chemoattractive molecules ex vivo. Interestingly, absence of proinflammatory cytokines and chemokines expression was observed in the lack of Piezo1 [75]. On the other hand, shear forces encounter while extravasating demonstrated Piezo1-dependent upregulation of ICAM-1 in ex vivo model. In a study of flow model, endothelial Piezo1 or Gaq/Ga11 specific depletion in mouse, exhibit diminished inflammatory signals and activation of integrin with regression of atherosclerosis in athero-susceptible region [95]. Conversely, in another study exploring the inflammatory role of Piezo1 in adipocytes, Piezo1 activation with its agonist Yoda1 show decreased TNF- $\alpha$ and MCP-1 expression, while blockade of Piezo1 with GsMTx4 increases TNFa, MCP-1, Il-1 $\beta$, and Il6 expression [96]. This suggest Piezo1 as potential hub in which distinct signaling pathways could diverge in responding to distinct mechanical cues and play a diverse role in different inflammatory mechanisms, in which it could trigger proinflammatory or anti-inflammatory and proatherogenic or atheroprotective signals depending on the type of stimuli (Figures $3 \& 4$ ), cell type and mechanism or pathway involved. Consistent with Solis findings, Piezo1 could encourage proinflammatory response that helps to get rid of harmful bacteria, while its deficiency could as well help prevent dysfunctional inflammatory injury in pulmonary fibrosis in mice. Additionally, myeloid cells Piezo1 depletion promoted endurance in polymicrobial sepsis and guard from cancer [97]. It's worth noting that Piezo1 channel via $\mathrm{Ca}^{2+}$ signaling may regulate a number of vital cellular activities [98] including immune/inflammatory cells. Consistent with the concept that $\mathrm{Ca}^{2+}$ signals control important cellular functions like mitosis, differentiating and migration, expression and functioning of several endocrine secretion as well as transcription molecules, (Figure 3) that control immune/inflammatory cells homeostasis [97, 99-101]. Therefore, Piezo1 channel can control inflammation and immunity via $\mathrm{Ca}^{2+}$ signaling as in pancreatitis, reported by Romac et al, in which Piezo1 agonist Yoda1 was applied and stimulated the influxes of $\mathrm{Ca}^{2+}$ that evokes calcium-dependent damage of the pancreas [102]. As versatile mechanosensor, Piezo1 may play a role in various pathways and unexplored mechanisms, in addition to these already known. In addition to inflammatory/immune cells mechanisms, several experiments including flow models have been tested 
and demonstrated Piezo1 as player in inflammation, immunity and atherosclerosis [103, 104]. Beside earlier reports including that of alberran Juarez and others, Zhang and colleagues also recently reported a unique Piezo1 mediated molecular process of inflammation and atherosclerosis via annexin A2 associated integrin triggering [105]. Piezo1 abundant responses to OS was also shown to result in elevated $\mathrm{Ca}^{2+}$ entry leading to Gq/G11 induced integrin a5 activating and ligating into a $5 \beta 1$ through translocating into lipid raft, thereby encouraging FAK-dependent NF- $\mathrm{KB}$ triggering and the expressing of proinflammatory molecules VCAM-1 and ICAM-1 [106] (Figure 3). Altogether, these findings support the idea that Piezo1 is not just limited to mediation of unidirectional or disturbed flow-evoked pro/anti-atherogenic signals, but also necessary for immune/inflammatory mechanisms of atherogenesis.

\subsection{Piezol signaling in vascular remodeling}

Remodeling is well recognized pathogenesis of CVDs which is triggered by various factors including variety of mechanical forces such as stretch, pressure, shear stress, cyclical stress that are fundamental in cardiovascular health and disease. SMCs and EC are major cells in the vessel, and they are continuously exposed to dynamic mechanical forces, which they sense via special mechanosensors such as Piezo1 and initiates regulatory responses. Mechanical force plays critical role in vessel remodeling, and mechanosensitive Piezo1 channel is well recognized sensor and transducer of various mechanical cues. Vascular remodeling comprises alteration in cellular proliferation, migration, apoptosis (discussed earlier) and ECM rearrangement including its synthetization and degrading [107, 108], hypertrophy, phenotypic switching, morphologic and functional alterations [109], the important mechanisms of atherosclerosis pathology and its progression. Study by Retailleau et al., precisely demonstrated earlier, the Piezo1 SMCs mechanosensing mechanism of vessel remodeling. The author reported that Piezo1 mediated the increase of cytosolic calcium as well as triggering of enzymatic activities (transglutaminase), necessary for arterial remodeling. He further ascertained that the depletion of smooth muscle Piezo1 in DOCA/salt/ uninephrectomy hypertensive mice resulted in decreased media thickening without visible changes in endothelial layer [110].

\subsubsection{Piezol mediated mechanical signals in cell proliferation, migration, apoptosis}

In cardiovascular, mechanical forces mediated by Piezo1, regulates various cellular activities like proliferation, migration, apoptosis. Occurrence of cellular proliferation, migration and apoptosis in macrophage, SMCs, and EC is crucial mechanism in the development of atherosclerosis plaque [111].

\subsubsection{Proliferation}

Smooth muscle cells. Cellular proliferation is a fundamental process involved in vascular health and disease (Figures 3 \& 4) [112-114] [115, 116]. Among vascular cells SMC proliferation is crucial in atherogenesis, and cyclical stretching mediated by Piezo1 is commonly known to raise the SMC proliferation (Figures 3 \& 4). Piezolis crucial for sensing and transduction of mechanical cues, including shear stress $[14,34]$ and stretching $[98,110$, 117-121], stretching was shown to work in synergy with OxLDL (oxidized lipoprotein) and norepinephrine in aggravating SMC proliferating by triggering of (ERK) signaling in both mice and rabbits [107, 122-125]. Piezo1 is necessary for shear sensing $[34,126,127]$, and shear stress was also known to speed up and regulate SMC proliferation via several mechanisms including MMP-2, MMP-9, PDGF, and the trigger of phosphatidylinositol 3 kinase (PI3K)protein kinase B, ERK1/2, Akt signaling [128]. Furthermore, upregulation of ERK and Akt trigger with sequential elevation of insulin-evoked cell proliferation was noted, following $15 \%$ stretch application to mice aortic SMCs [107, 128, 129].

Endothelial cells. In response to cyclical stretching known to be sensed and transduced by Piezo1 [111], EC could proliferate in a mechanism that necessitates cell-cell interaction. Piezo1 was previously identified as significant player in angiogenesis, and EC proliferates, migrates, and coalesces in response to angiogenic stimulus, forming primitive vessel labyrinths that develop and remodels [108, 130]. Additionally, excessive ECs proliferation was reported in supraphysiologic stretching, as seen from increased HUVEC expression of the oncogene c-Myc [108]. This might significantly encourage vascular disorders including atherosclerosis, by inducing thickening of intima.

Macrophages. Macrophages also sense cyclic pressure through Piezo1 resulting in expression of several inflammatory mediators including of IL-1 $\beta$ $[75,131]$, IL-6, IL-8 as well as TNF-a [132] (Figures 3 \& $4)$, which instigate inflammation as well as matrix metalloproteinases that stimulate cell proliferation [133] and induce plaque weakening [134-137]. Additionally, macrophage activities can be control by Piezo1 through various mechanical cues, as it is highly expressed and functions in macrophage [75], considering matrix stiffness and topology were among mechanical factors that control the differentiating, functioning and proliferating of 
macrophages [132]. Robbins reported that plaque macrophages accumulations and replenishing relies on resident macrophages proliferation instead of monocyte entrance [137, 138] (Figures 3 \& 4), demonstrating and proving the significance of cell proliferation in atherogenesis, through Piezo1 mediated mechano-signaling.
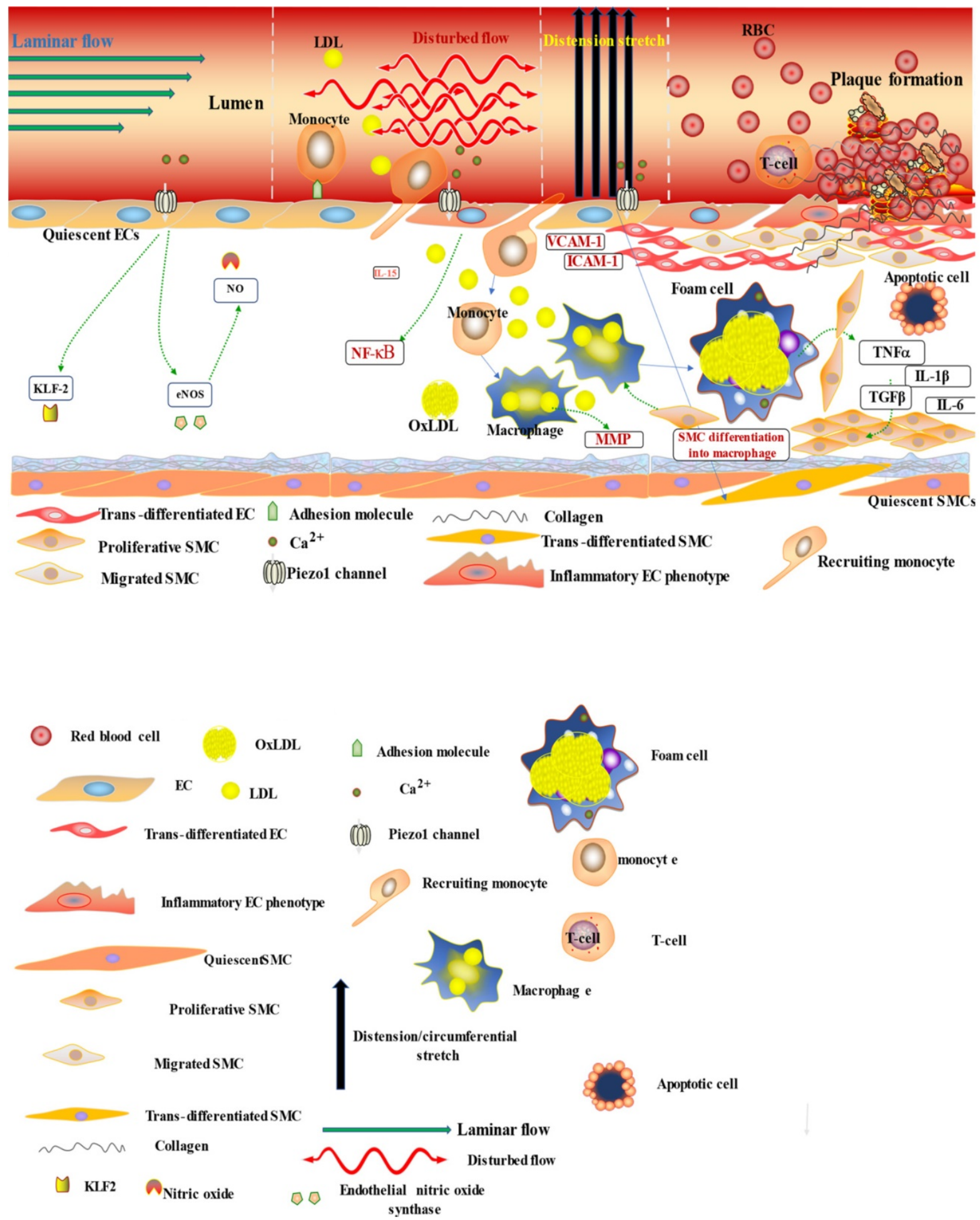

Figure 3. The diagram illustrates the atherogenic role of Piezol in different mechanical signals; first segment (vessel lumen) initiating Piezol dependent $\mathrm{Ca}^{2+}$ entry and trigger of atheroprotective signaling through EC activation and regulation of gene expression KLF2, NO and maintaining noninflammatory, non-proliferative/migrative quiescent EC. Second segment turbulent/oscillatory flow (red arrow) Piezol dependent triggering of proatherosclerotic signaling via EC activation to proinflammatory phenotype and immune/inflammatory cell recruitment, proinflammatory gene expression NF-KB, cytokine release (VCAM-1 ICAM-1) and result in cell proliferation and migration, leading to macrophage accumulation and form cell formation and atherosclerosis development. In addition to second segment, third segment distension/circumferential stretches (blue arrow) Piezol dependent stretch stimulation leading to trans-differentiation of EC to SMC phenotype, and SMC into macrophages, proliferation migration and apoptosis, release of growth factors TGF $\beta$ and cytokines TNFa, IL-6, ILI $\beta$, MCP-1 etc, contributing to disease progression and plague rupture. Fourth segment advanced atherosclerotic plaque and thrombus formation. 

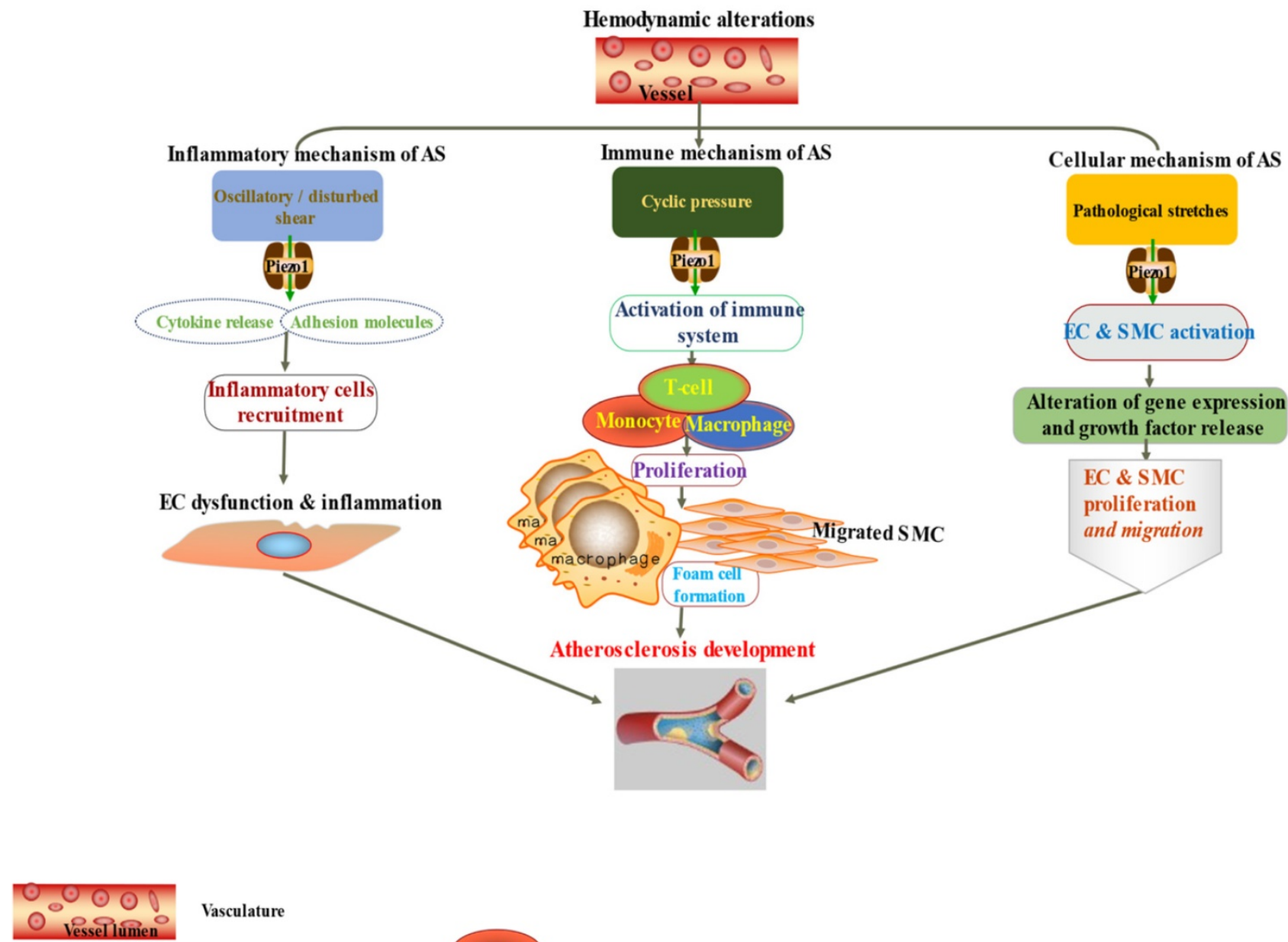

Vasculature

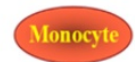

Pịpl Piezolchannel

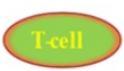

Endothelial cell

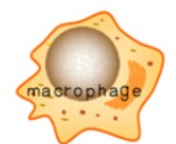

Proliferative macrophage

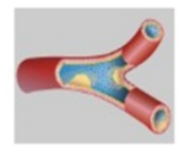

Atherosclerosis formatio n

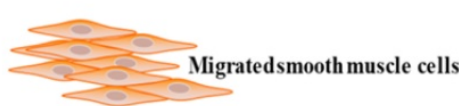

Figure 4. The diagram depicted Piezol dependent signaling; (left) inflammatory mechanism of AS by disturbed/oscillatory shear leading to the release of cytokines and adhesion molecule, inflammatory cell recruitment, EC dysfunction and inflammation, facilitating the development of AS, (middle) Piezol dependent activation of immune cells by cyclic pressure result in cytokine release, proliferation migration form cell formation and disease development, (left)Piezol dependent stretch activation of EC and SMC leading to changes in gene expression and growth factor secretion and result in proliferation and migration facilitating the development of atherosclerosis.

\subsubsection{Migration}

Endothelial cell. Studies reported the crucial role of Piezo1 mediated endothelial migrating toward VEGF, and eNOS triggering, result in NO production, crucial for cell migrating control amid vasculogenesis [27]. It was also reported that, by responding to shear stress Piezo1 promote migrating and aligning in ECs. Recent study revealed the elevation in migrating speed in HEK293 cell line, noted as a result of overexpressing Piezo1, and there was nearly total inhibition of migrating after application of GsMTx4 or $A \beta$ peptide [127]. Therefore, these data suggest versatile migrative functions of Piezo1 with cell specificity in selective mechanism and signaling pathways.

Smooth muscle cells. Cellular migration is 
significant physiological process for development and tissue homeostasis or defense as well as in disease process. Mechanosensitive Piezo1 channel senses and transduces forces including cyclic pressure/stretches, shear stress, and membrane tensions which serves crucial function in cell migration. Both EC \&VSMC experiences various forms of mechanical stresses, senses via Piezo1, arising from hemodynamic changes as in blood flow/pressure and circumferential stretches in (Figure 3), which results in aligning and phenotypic switching, leading to elevation in migrating and proliferating. In response to various mechanical stimuli VSMC migrates from media to intima as in atherogenesis (Figures $3 \& 4$ ) or healing, following vascular damage [107, 139, 140], and several mechanical stresses mediated by Piezo1 was reported to impacts cellular migrating through different mechanisms [141-144], for example in human VSMCs activation of migration via triggering of nuclear factor of triggered T-cells 5 nuclear translocating by 13\% stretching for $24 \mathrm{~h}$, and increased migration through ERK dependent raised of myocardin expressing, by $20 \%$ stretching in mice VSMC [107]. VSMC migration is well recognized mechanism of atherogenesis which induced by multiple factors including mechanical force which led to the migration of these cells from its normal location (media) to intima and proliferate as discussed above, contributing to plaque development and disease progression. Additionally, recent studies demonstrated the mechanical forces effects on both VSMC migration and phenotype alteration [145-147] (Figure 3) and release of various chemicals leading to pathological intimal thickening and plaque formation, the fundamental mechanism of atherogenesis.

Macrophages. In mechanosensitive tissues mechanical signal controls various macrophage functions including inflammatory responses [132]. Immune cells, including macrophages, encounter various mechanical forces, such as shear stress mediated by Piezo1 in the circulation amid extravasation, and membrane deformation amid migration to the injury site. Beside migratory role of Piezo1 in various cell including stem cells [141], pancreatic satellite cells [143], and cancers [18], recent study reported that, Piezo1-dependent mechanical triggering of macrophages ex vivo, activates a robust and specific expression of pro-inflammatory as well as chemoattractive mediators [75], thus, initiating and promoting macrophage migratory responses to the inflammatory tissues.

\subsubsection{Apoptosis}

Endothelial cells. Shear stress mediated by Piezo1 is recognized sensitizer of Tumor necrosis factor a (TNF-a)-related apoptosis-inducing ligand (TRAIL) in human umbilical vein endothelial cells (HUVECs) and cancer cells. Hope et al. reported the massive apoptosis elevation in number of cell lines (MDA-MB-231, COLO 205 and PC3 cells) after application of both Piezo1 agonist Yoda1 and Trail, which happen through Piezo1 dependent signaling via $\mathrm{Ca}^{2+}$ influxes which triggers calpain, while application of GsMTx-4 decreased shear induced TRAIL stimulation [148].

Smooth muscle cells. Mechanical force affects apoptosis and viability of vascular cells including ECs and VSMCs as they are exposes to different forms of mechanical stress of various intensity and magnitudes. Currently, Piezo1 is recognized as important player in mechanosignaling. Growing number of reports are increasingly proving the relevance of mechanical forces in cardiovascular apoptosis [149, 150]. Apoptosis dysregulating is among the crucial mechanisms in CVD pathologies and raise in apoptosis was reported to be associated with atherosclerosis and heart failure. Piezo1 is essential for sensing and transduction of variety mechanical cues, and various mechanical forces are involved in the upregulation of VSMC apoptosis [107, 151, 152] (Figure 3). Study reported that application of stretching encourages cell death via the inducting of p53 upregulated apoptotic regulator in human VSMC with $\beta 1$-integrin trigger of p38 MAPK in VSMCs of mice [107]. Another study revealed that mechanical stressing evoked VSMC apoptosis rely mainly on p53 and mechanical stresses was shown to triggers p53 through Rac and p38MAPK mechanism [125].

Other cell types. Recent study reported that in alveoli, amid (ARDS) acute respiratory distress syndrome, stimulation of Piezo1 by mechanical stretching result in elevated intracellular $\mathrm{Ca}^{2+}$ evoked type II pneumocytes apoptosis, whereas, reduction in apoptosis was observed in the absence of Piezo1, which are in association with Bcl-2 pathway [153]. Furthermore, another study of ex vivo model using shear, revealed Piezo1 mechanical force mediation of $\mathrm{Ca}^{2+}$ evoked Osteosarcoma cell apoptosis and inhibit proliferation. Additionally, another study in vivo reported growth encouragement of these cells after abrogation of Piezo1 gene expression in immunodeficient mouse [18, 154]. Altogether, these results demonstrate the significance of Piezo1 in different apoptotic mechanisms and emphasizes its involvement in atherogenesis.

\section{Piezo1 pharmacology}

\subsection{Piezol activators}

Apart from mechanical forces, Piezo1 can chemically be gated. Recent studies, through high 
throughput screening technologies, small chemical compounds such as Yoda1 [165], including the exploration of its Piezo1 activating mechanism and binding site [166], and Jedi1/2 [74] was revealed (Table 3). Out of these compounds, Yoda1 is the most potent with maximum effective concentration (EC50) and bounding affinity to purified Piezo1 ranging from 10 to $50 \mu \mathrm{M}$. additionally, Yoda1 decreases the mechanical triggering threshold by balancing the gated conformations of the channel, which enables partial trigger of the channel without mechanical stimulus. Piezo1 was reported to have three possible interaction sites with Yoda1, 1 per subdomain. By characterizing chimeric hybrid channels combining Yoda1 sensitive and non-sensitive subdomains, the author demonstrated that, in one channel, only one sensitive subdomain is needed, and enough for Yoda1 evoked Piezo1 gating [53, 166] (Table 2). According to their finding, keeping a single pore of Piezo1 opened, the other subdomain stays gated. Furthermore, Piezo1\&2 chimeric analysis show that the area with residues 1,961-2,063 is crucial for Yoda1 evoked Piezo1 trigger [166] (Tables 2 \& 3), indicating the potency and strong affinity of Yoda1 to Piezo1, validating it as important tool in Piezo1 research. On the other hand, Jedi $1 \& 2$ are Piezo1 agonists with higher water solubility, prompt onset and rapid decaying than Yoda1. They, as well, initiate Piezo1 mechanical sensitivity and decelerate the inactivating of Piezo1 via extracellular side. For triggering and modulating Piezo1, Jedi acts on the site near the blade-beam activation thoroughfare distinctive from that triggered by Yoda1. Additionally, Piezo1 poking currents were synergistically evoked after coapplying of Yoda1 and Jedi $[45,74]$, which suggests Yoda1 and Jedi modulation of Piezo1 could be via distinctive mechanisms. Jedi 1 \& 2 bind to 1-2,190 residues rather than CED, demonstrating possible Jedi 1 \& 2 bounding sites as ELs of the propeller blades as shown by surface plasma binding assay. For Jedi evoked Piezo1 trigger the important mechanical transduction portions EL15-16 and EL19-20 of distal blades and L1342/L1345 of the beam proximity is required demonstrating that Yoda1 may be acting downstream of the beam whilst Jedi upstream of the blade (Tables 2 \& 3). Studies demonstrated that various mutants abrogate different Piezo1 triggering force while others remain spared or other way round. Mutating of A2094W disrupted Yoda1 and Jedi1 sensitiveness while maintain that of membrane stretching. Similarly, mutants of beam L1342A/ L1345A abrogates both mechanical triggering via cell poking and chemical stimulation of Yoda1 and Jedi1 while remain sensitive to stretching $[74,166]$. Mechanical trigger of stretching [167] and swelling was abolished by R2135A mutant without affecting Jedi2 and Yoda1 sensitiveness [166].

Table 3. Summarization of current Piezol pharmacology

\begin{tabular}{|c|c|c|c|}
\hline \multirow{2}{*}{\multicolumn{2}{|c|}{$\begin{array}{l}\text { Agents } \\
\text { Activating agents }\end{array}$}} & Binding site (domain) & References \\
\hline & \multicolumn{3}{|c|}{ Activating agents } \\
\hline \multirow[t]{2}{*}{ Specific } & Yoda & C-terminal (ATM area) & {$[53,165]$} \\
\hline & Jedi1/2 & L15-16/L19-20 area & $\begin{array}{l}{[45,74} \\
179]\end{array}$ \\
\hline \multicolumn{4}{|c|}{ Modulating agents } \\
\hline & & \multicolumn{2}{|c|}{$\begin{array}{l}\text { Membrane lipid environmental } \\
\text { alterations }\end{array}$} \\
\hline \multirow[t]{2}{*}{ Unspecific } & $\begin{array}{l}\text { Unsaturated-Docosahexaenoic } \\
\text { acid }\end{array}$ & Slow inactivation & {$[180]$} \\
\hline & Saturated-Margaric acid & Speedup inactivation & \\
\hline \multicolumn{4}{|c|}{ Inhibiting agents } \\
\hline \multirow[t]{2}{*}{ Unspecific } & GsMTx4 & Pore of the channel & {$[179,181]$} \\
\hline & $\begin{array}{l}\text { Ruthenium Red } \\
\text { gadolinium }\end{array}$ & & \\
\hline \multirow[t]{2}{*}{ Specific } & Tubeimoside1 & Compete with Yoda1 & {$[179,181]$} \\
\hline & Dooku1 & & \\
\hline
\end{tabular}

\subsection{Piezol inhibitors}

As new cation channel with versatile cardiovascular functions involving complex mechanisms and related pathway its pharmacology is still immature. Till date, GsMTx-4 [168-171], gadolinium III $(\mathrm{Gd} 3+)[18,157]$ Ruthenium Red (RR) $[29,30]$, are the only recognized and widely used generic blockers of Piezo1, also used to inhibits several ion channels Table 3. GsMTx-4 is peptide toxin with reversible inhibition of Piezo1 activities and maximum $\mathrm{Kd}$ of 2 $\mu \mathrm{M}$, commonly employed in Piezo1 researches. GsMTx4 modifies Piezo1 channel opening, its (L- and D-form) enantiomers blocks Piezo1, demonstrating its possible modulation of membrane tension rather than direct action on the channel itself. GsMTx-4 and RR have been employed in probing the Piezo1 triggering mechanisms as well as ion-conducting pore. RR If administered from extracellular side, inhibits the inward rather than outward current of mPiezo1/2 alone, suggesting its pore-inhibiting mechanism [45]. Recent studies reported the recognition of other molecules, including Yoda1 analog named Dooku1 [172] and the most recent compound Tubeimoside1 (TBMS1) extracted from Bolbostemma [173], both with reversible antagonizing capability of Yoda1-evoked Piezo1 trigger (Table 3). They were reported to exert their effect through selective binding site competition with Yoda1. Additionally, an amphipathic Abeta $(A \beta)$ peptide was revealed to inhibit Piezo1 shear responses within the concentrations of fento to Pico molar. A $\beta$ peptides are a membrane mechanic modulator with oligomer that was verified to have lesser potency. Nevertheless, by utilizing patch clamp, its inhibiting activity was not seen on Piezo1, using same concentration which blocked shear responses [127]. However, the 
realization of these agents, both agonists and antagonists along with the latest advancements of Piezo1 topographic structure, could surely facilitates Piezo1 research for exploring and deep understanding of its structure-function-relationship in different conformational states and possible Piezo1 mechanisms in health and disease conditions.

\subsection{Piezol channels drugability and therapeutic potentials}

Aforementioned works including many not cited here, indicated the significance of Piezo1 in various pathophysiological processes, specifically cardiovascular. Due to the infancy of both Piezo1 and its pharmacology research, a lot is not yet known, but its functions are still emerging. The realization of Piezo1 and its pharmacology (Table 3) provides excellent opportunity, as it may be considered or used as indicator/biomarker for diagnostic, prognostic [174] and genealogical target for therapeutic approaches. Identifying Piezo1 as prognostic marker and low life expectancy related to its high expression in glioma patient [175] emphasizes the idea that Piezo1 could be attractive candidate for various clinical aspects of diseases including atherosclerosis in the near feature. Considering that Piezo1 is upregulated in some cells while downregulated in others, depending on cell type and mechanisms or pathway involved, the discovery of pharmacological agents (discussed above) for selective inhibition or activation of Piezo1 will be therapeutically inevitable. On the other hand, mechanomedicine/mechanotherapeutics [150, 176], emerged as new approach that demonstrate Piezo1 as doubtless and promising therapeutic target for cardiovascular diseases. As mechanical cues are among key determinants of cardiovascular homeostasis, sub-physiological and supraphysiologic mechanical stresses are implicated in abnormal proliferation, migration, apoptosis as well as immune/inflammatory processes and atherosclerosis, including other CVDs, and mechanomedicine could provide hopeful outlook for selective tuning of Piezo1 mechanotransduction for mechanostatic restoration and maintenance. Additionally, another therapeutic idea through Piezo1 is also promising approach, in which cellular responses can be mechanically regulated through modulation of the mechanosensory genes-circuit. Recent study disclosed an amazing novel immunotherapeutic innovation called chimeric antigen T- cell receptor (CAR-T cell), with efficacy against multiple soft tumors. For aimed and regulated deliverance, mechanosensitive CAR $\mathrm{T}$ cell was manipulated through regulating of mechanosensory capacity of Piezo1, in order that mechanical perturbation by ultrasound wave could trigger the
CART T cells within selected area. It is a therapeutic approach with high geotemporal accuracy which could be employed for remote control stimulating of various cell species $[177,178]$, hence, CAR could also be employed for targeting immune/inflammatory and other related mechanisms of atherosclerosis. Altogether, these data demonstrate and validate the drugability and therapeutic potential of Piezo1 in cardiovascular, particularly atherosclerosis.

\section{Perspectives}

Piezo1 discovery, emergence of its roles in various aspects of cardiovascular and rapid development of its research demonstrated a promising potential of the field towards novel therapeutic innovation for clinical application targeting atherosclerosis and other CVDs. Regardless of the infancy of the field, recent advancement in the realization of Piezo1 topographical structure and the outstanding breakthrough of its pharmacological agents indicate Piezo1 as doubtless target for novel therapeutic approaches in cardiovascular. Despite lack of potent agonists and specificity of Piezo1 blockers, both agents are widely accepted and employed as tools in Piezo1 research. Among the challenges of Piezo1 research are; wide range of expression and functions in multiple cell types, limited knowledge of Piezo1 functions in association with other proteins, such as interplay with cytoskeletal structures [27], other membrane channels like Piezo2 as in Baroreceptor reflex [163], and TRPV4 [182-184] etc. Nevertheless, in-depth understanding of the channels and related pathways overlapping, cross-talk as well as kinetic properties, cell specificity, and structure-function-relationship are required for elucidating how Piezo1 regulates particular disease process specifically atherosclerosis, to develop a high precision therapeutic approach through rational design of specific Piezo1 agonists and antagonists for obtaining effective therapies as well as avoiding or minimizing unwanted effects.

\section{Conclusion}

Due to relevance of mechanical forces in cardiovascular disease, mechanotransduction has attracts much attention. The role of Piezo1 mechanotransduction in vascular, immune/inflammatory cells, indicates that Piezo1 is involved in atherosclerosis, therefore Piezo1 is a promising candidate for therapeutic innovation against atherosclerosis and other CVDs. It may be engaged in number of unexplored pathophysiological mechanisms through different signaling. For example, Piezo1 is key transducer of mechanical cues into $\mathrm{Ca}^{2+}$ dependent signaling. Hence, through calcium, Piezo1 may 
contribute to atherosclerosis, though further study is required for this concept. Additionally, Piezo1 mechanical triggering leads to intracellular $\mathrm{Ca}^{2+}$ elevation and might consequently trigger the Akt/MTOR pathways through calmodulin (CaM)/CaM dependent protein kinases II (CaMII) which enhances cell proliferation and migration [18]. Intriguingly EC was found to be trans-differentiated into SMCs with elevated markers of SMC including a-SMA, SM22-a, SM MHC, calponin as well as caldesmon1 upon exposure to mechanical stretching $[108,130,185,186]$, which is known to be sensed by Piezo1. This stretch-induced plasticity of EC could augment atherosclerosis progression, and might be Piezo1-dependent. This necessitates the additional effort to further explore Piezo1-induced-mechanical effects on vascular cells. Nevertheless, Piezo1 research has witnessed rapid development, for example recent advancement in high throughput technology such as atomic force microscope, patch clamp electrophysiology, cryo-electron microscopy including other computational biological tools and gene editing technology. We believe that through the utilization of these technologies Piezo1 could be studied further leading to insight into various CVDs and other diseases like cancer. Mechanomedicine/mechanotherapeutics using Piezo1 is among the promising strategies, for example in cardiovascular, selective tuning of Piezo1 to control the cellular vulnerability to excessive sub-physiologic or supraphysiologic mechanical forces, might block deleterious proliferation, migration, apoptosis or inflammation, to prevent the disease initiation or treatment through the reversal of disease pathogenesis. Piezo1 could also be employed for immunotherapy, especial using CAR for selective activation or modulating of several immune cells like monocyte/macrophage and T-cells either systemic or locally, to treat atherosclerosis and other CVDs, including COVID-19 and cancer as already reported for different cancer treatment strategies. Lastly, further elucidation of Piezo1 mechanisms regulating atherosclerosis should be the priority for future research as initial step for developing novel and effective therapeutic strategies for treating atherosclerosis.

\section{Abbreviations}

CVDs: Cardiovascular disease; VEC: Vascular endothelial cell; RBCs: Red Blood Cells; VEGF: Vascular Endothelial Growth Factor; PDGF: Platelet Derived Growth Factor; IL: Interleukin; MCP-1: Monocyte chemotactic protein-1; PECAM-1: Platelet Endothelial cell Adhesion Molecule; ICAM-1: Intercellular Adhesion Molecule; VCAM: Vascular Cell Adhesion Molecule; KLF: Kruppel Like Factor;
NF-кB: Nuclear Factor Kappa B; eNOS: endothelial Nitric Oxide Synthase; ROX: Reactive Oxygen Species; HUVECs: Human umbilical vein endothelial cells.

\section{Acknowledgements}

Thanks for the support by the National Natural Science Foundation of China, Collaborative Innovation Center for Prevention and Treatment of Cardiovascular Disease of Sichuan Province, and Luzhou Municipal People's Government Southwestern Medical University Science and Technology Strategic.

\section{Author Contributions}

All authors contributed greatly for the realization of the work in different aspects of the manuscript, ranging from conceptualization, study design, execution, analytical interpretation, supervision and publication.

\section{Funding Information}

This work is supported by the National Natural Science Foundation of China [No.: 31860261], and [No.: 11462022], together with "Collaborative Innovation Center for Prevention and Treatment of Cardiovascular Disease of Sichuan Province" in 2019 [No.: xtcx2019-03 and No.: xtcx2019-04], and Luzhou Municipal People's Government - Southwest Medical University Science and Technology Strategic Cooperation Project (No.: 2018LZXNYD-ZK27 and No.: 2018LZXNYD-ZK40) 2018.

\section{Competing Interests}

The authors have declared that no competing interest exists.

\section{References}

1. Libby P. Inflammation in atherosclerosis. Arterioscler Thromb Vasc Biol. 2012; 32: 2045-51.

2. Pourcet B, Staels B. Alternative macrophages in atherosclerosis: not always protective! J Clin Invest. 2018; 128: 910-2.

3. Ross R. Atherosclerosis--an inflammatory disease. N Engl J Med. 1999; 340: 115-26.

4. Ruscica M, Corsini A, Ferri N, Banach M, Sirtori CR. Clinical approach to the inflammatory etiology of cardiovascular diseases. Pharmacological Research. 2020; 159: 104916.

5. O'Morain VL, Ramji DP. The Potential of Probiotics in the Prevention and Treatment of Atherosclerosis. Mol Nutr Food Res. 2020; 64: e1900797.

6. Gistera A, Robertson AK, Andersson J, Ketelhuth DF, Ovchinnikova O, Nilsson SK, et al. Transforming growth factor-beta signaling in $\mathrm{T}$ cells promotes stabilization of atherosclerotic plaques through an interleukin-17-dependent pathway. Sci Transl Med. 2013; 5: 196ra00.

7. Song P, Fang Z, Wang H, Cai Y, Rahimi K, Zhu Y, et al. Global and regional prevalence, burden, and risk factors for carotid atherosclerosis: a systematic review, meta-analysis, and modelling study. The Lancet Global Health. 2020; 8: e721-e9.

8. Din AU, Hassan A, Zhu Y, Yin T, Gregersen H, Wang G. Amelioration of TMAO through probiotics and its potential role in atherosclerosis. Appl Microbiol Biotechnol. 2019; 103: 9217-28.

9. Chistiakov DA, Orekhov AN, Bobryshev YV. Effects of shear stress on endothelial cells: go with the flow. Acta Physiol (Oxf). 2017; 219: 382-408. 
10. Zhou J, Li YS, Chien S. Shear stress-initiated signaling and its regulation of endothelial function. Arterioscler Thromb Vasc Biol. 2014; 34: 2191-8.

11. Lan L, Liu H, Ip V, Soo Y, Abrigo J, Fan F, et al. Regional High Wall Shear Stress Associated With Stenosis Regression in Symptomatic Intracranial Atherosclerotic Disease. Stroke. STROKEAHA120030615.

12. Bai L, Shyy JYP. Shear Stress Regulation of Endothelium: A Double-edged Sword. J Transl Int Med. 2018; 6: 58-61.

13. Zhao Y, Ren P, Li Q, Umar SA, Yang T, Dong Y, et al. Low Shear Stress Upregulates CX3CR1 Expression by Inducing VCAM-1 via the NF-kappaB Pathway in Vascular Endothelial Cells. Cell Biochem Biophys. 2020; 78: 383-9.

14. Beech DJ, Kalli AC. Force Sensing by Piezo Channels in Cardiovascular Health and Disease. Arteriosclerosis, Thrombosis, and Vascular Biology. 2019; 39: 2228-39.

15. Uzarski JS, Scott EW, McFetridge PS. Adaptation of endothelial cells to physiologically-modeled, variable shear stress. PLoS One. 2013; 8: e57004.

16. Bai X, Bouffard J, Lord A, Brugman K, Sternberg PW, Cram EJ, et al. Caenorhabditis elegans PIEZO channel coordinates multiple reproductive tissues to govern ovulation. Elife. 2020; 9.

17. Chang JE, Buechler MB, Gressier E, Turley SJ, Carroll MC. Mechanosensing by Peyer's patch stroma regulates lymphocyte migration and mucosal antibody responses. Nat Immunol. 2019; 20: 1506-16.

18. De Felice D, Alaimo A. Mechanosensitive Piezo Channels in Cancer: Focus on altered Calcium Signaling in Cancer Cells and in Tumor Progression. Cancers (Basel). 2020; 12

19. Song J, Liu L, Lv L, Hu S, Tariq A, Wang W, et al. Fluid shear stress induces Runx-2 expression via upregulation of PIEZO1 in MC3T3-E1 cells. Cell Biol Int. 2020; 44: 1491-502.

20. Sun Y, Li M, Liu G, Zhang X, Zhi L, Zhao J, et al. The function of Piezo1 in colon cancer metastasis and its potential regulatory mechanism. J Cancer Res Clin Oncol. 2020; 146: 1139-52.

21. Velasco-Estevez M, Gadalla KKE, Linan-Barba N, Cobb S, Dev KK, Sheridan GK. Inhibition of Piezo1 attenuates demyelination in the central nervous system. Glia. 2020; 68: 356-75.

22. Zhong M, Komarova Y, Rehman J, Malik AB. Mechanosensing Piezo channels in tissue homeostasis including their role in lungs. Pulm Circ. 2018; 8: 2045894018767393.

23. Albuisson J, Murthy SE, Bandell M, Coste B, Louis-Dit-Picard H, Mathur J, et al. Dehydrated hereditary stomatocytosis linked to gain-of-function mutations in mechanically activated PIEZO1 ion channels. Nat Commun. 2013; 4: 1884.

24. Lukacs V, Mathur J, Mao R, Bayrak-Toydemir P, Procter M, Cahalan SM, et al. Impaired PIEZO1 function in patients with a novel autosomal recessive congenital lymphatic dysplasia. Nat Commun. 2015; 6: 8329.

25. Fotiou E, Martin-Almedina S, Simpson MA, Lin S, Gordon K, Brice G, et al. Novel mutations in PIEZO1 cause an autosomal recessive generalized lymphatic dysplasia with non-immune hydrops fetalis. Nat Commun. 2015; 6: 8085.

26. Mastromoro G, Guadagnolo D, Giancotti A, Di Gregorio MG, Marchionni E, Vena F, et al. Recurrent prenatal PIEZO1-related lymphatic dysplasia: Expanding molecular and ultrasound findings. Eur J Med Genet. 2021; 64: 104106.

27. Nourse JL, Pathak MM. How cells channel their stress: Interplay between Piezo1 and the cytoskeleton. Semin Cell Dev Biol. 2017; 71: 3-12.

28. Bagriantsev SN, Gracheva EO, Gallagher PG. Piezo proteins: regulators of mechanosensation and other cellular processes. J Biol Chem. 2014; 289: 31673-81.

29. Coste B, Mathur J, Schmidt M, Earley TJ, Ranade S, Petrus MJ, et al. Piezo1 and Piezo2 are essential components of distinct mechanically activated cation channels. Science. 2010; 330: 55-60.

30. Coste B, Xiao B, Santos JS, Syeda R, Grandl J, Spencer KS, et al. Piezo proteins are pore-forming subunits of mechanically activated channels. Nature. 2012; 483: 176-81.

31. Roh J, Hwang SM, Lee SH, Lee K, Kim YH, Park CK. Functional Expression of Piezo1 in Dorsal Root Ganglion (DRG) Neurons. Int J Mol Sci. 2020; 21.

32. Rode B, Shi J, Endesh N, Drinkhill MJ, Webster PJ, Lotteau SJ, et al. Piezo1 channels sense whole body physical activity to reset cardiovascular homeostasis and enhance performance. Nat Commun. 2017; 8: 350 .

33. Nonomura K, Lukacs V, Sweet DT, Goddard LM, Kanie A, Whitwam T, et al. Mechanically activated ion channel PIEZO1 is required for lymphatic valve formation. Proc Natl Acad Sci U S A. 2018; 115: $12817-22$
34. Choi D, Park E, Jung E, Cha B, Lee S, Yu J, et al. Piezo1 incorporates mechanical force signals into the genetic program that governs lymphatic valve development and maintenance. JCI Insight. 2019; 4.

35. Woo SH, Lukacs V, de Nooij JC, Zaytseva D, Criddle CR, Francisco A, et al. Piezo2 is the principal mechanotransduction channel for proprioception. Nat Neurosci. 2015; 18: 1756-62.

36. Lewis AH, Cui AF, McDonald MF, Grandl J. Transduction of Repetitive Mechanical Stimuli by Piezo1 and Piezo2 Ion Channels. Cell Rep. 2017; 19: $2572-85$

37. Li J, Hou B, Tumova S, Muraki K, Bruns A, Ludlow MJ, et al. Piezo1 integration of vascular architecture with physiological force. Nature. 2014; 515: 279-82.

38. Hyman AJ, Tumova S, Beech DJ. Piezo1 Channels in Vascular Development and the Sensing of Shear Stress. Curr Top Membr. 2017; 79: 37-57.

39. Ranade SS, Woo SH, Dubin AE, Moshourab RA, Wetzel C, Petrus M, et al. Piezo2 is the major transducer of mechanical forces for touch sensation in mice. Nature. 2014; 516: 121-5.

40. Gottlieb PA. Current Topics in Membranes, Volume 79 Piezo channels. In: Gottlieb PA, editor. Current Topics in Membranes: Academic Press; 2017. p. ii.

41. Guo J, Gu D, Zhao T, Zhao Z, Xiong Y, Sun M, et al. Trends in Piezo Channel Research Over the Past Decade: A Bibliometric Analysis. Front Pharmacol. 2021; 12: 668714.

42. Lim CG, Jang J, Kim C. Cellular machinery for sensing mechanical force. BMB Rep. 2018; 51: 623-9.

43. Zhao Q, Zhou H, Chi S, Wang Y, Wang J, Geng J, et al. Structure and mechanogating mechanism of the Piezo1 channel. Nature. 2018; 554: 487-92.

44. Zheng W, Gracheva EO, Bagriantsev SN. A hydrophobic gate in the inner pore helix is the major determinant of inactivation in mechanosensitive Piezo channels. Elife. 2019; 8.

45. Xiao B. Levering Mechanically Activated Piezo Channels for Potential Pharmacological Intervention. Annu Rev Pharmacol Toxicol. 2020; 60: 195-218.

46. Geng J, Zhao Q, Zhang T, Xiao B. In Touch With the Mechanosensitive Piezo Channels: Structure, Ion Permeation, and Mechanotransduction. Curr Top Membr. 2017; 79: 159-95.

47. Douguet D, Patel A, Xu A, Vanhoutte PM, Honore E. Piezo Ion Channels in Cardiovascular Mechanobiology. Trends Pharmacol Sci. 2019; 40: 956-70.

48. Zhao Q, Zhou H, Li X, Xiao B. The mechanosensitive Piezo1 channel: a three-bladed propeller-like structure and a lever-like mechanogating mechanism. FEBS J. 2019; 286: 2461-70.

49. Fang XZ, Zhou T, Xu JQ, Wang YX, Sun MM, He YJ, et al. Structure, kinetic properties and biological function of mechanosensitive Piezo channels. Cell Biosci. 2021; 11: 13

50. Jiang Y, Yang X, Jiang J, Xiao B. Structural Designs and Mechanogating Mechanisms of the Mechanosensitive Piezo Channels. Trends Biochem Sci. 2021.

51. Wang L, Zhou H, Zhang M, Liu W, Deng T, Zhao Q, et al. Structure and mechanogating of the mammalian tactile channel PIEZO2. Nature. 2019; 573: 225-9.

52. Taberner FJ, Prato V, Schaefer I, Schrenk-Siemens K, Heppenstall PA, Lechner SG. Structure-guided examination of the mechanogating mechanism of PIEZO2. Proc Natl Acad Sci U S A. 2019; 116: 14260-9.

53. Lacroix JJ, Botello-Smith WM, Luo Y. Probing the gating mechanism of the mechanosensitive channel Piezo1 with the small molecule Yoda1. Nat Commun. 2018; 9: 2029.

54. Lewis AH, Grandl J. Inactivation Kinetics and Mechanical Gating of Piezo1 Ion Channels Depend on Subdomains within the Cap. Cell Rep. 2020: 30: 870-80 e2.

55. Wu J, Young M, Lewis AH, Martfeld AN, Kalmeta B, Grandl J. Inactivation of Mechanically Activated Piezo1 Ion Channels Is Determined by the C-Terminal Extracellular Domain and the Inner Pore Helix. Cell Rep. 2017; 21: 2357-66.

56. Alper SL. Genetic Diseases of PIEZO1 and PIEZO2 Dysfunction. Curr Top Membr. 2017; 79: 97-134.

57. Mansoor SE, Lu W, Oosterheert W, Shekhar M, Tajkhorshid E, Gouaux E. X-ray structures define human $\mathrm{P} 2 \mathrm{X}(3)$ receptor gating cycle and antagonist action. Nature. 2016; 538: 66-71.

58. Bae C, Gnanasambandam R, Nicolai C, Sachs F, Gottlieb PA. Xerocytosis is caused by mutations that alter the kinetics of the mechanosensitive channel PIEZO1. Proc Natl Acad Sci U S A. 2013; 110: E1162-8.

59. Saotome K, Murthy SE, Kefauver JM, Whitwam T, Patapoutian A, Ward AB. Structure of the mechanically activated ion channel Piezo1. Nature. 2018; 554: 481-6.

60. Ridone P, Grage SL, Patkunarajah A, Battle AR, Ulrich AS, Martinac B. "Force-from-lipids" gating of mechanosensitive channels modulated by 
PUFAs. Journal of the Mechanical Behavior of Biomedical Materials. 2018; 79: 158-67.

61. Cox CD, Bavi N, Martinac B. Chapter Three - Origin of the Force: The Force-From-Lipids Principle Applied to Piezo Channels. In: Gottlieb PA, editor. Current Topics in Membranes: Academic Press; 2017. p. 59-96.

62. Shi J, Rode B, Beech DJ. Activation of Endogenous Piezo1 Channels by Shear Stress in Excised Membrane Patches. Biophysical Journal. 2018; 114: $114 \mathrm{a}$

63. Wu J, Goyal R, Grandl J. Localized force application reveals mechanically sensitive domains of Piezo1. Nat Commun. 2016; 7: 12939.

64. Lin YC, Guo YR, Miyagi A, Levring J, MacKinnon R, Scheuring S. Force-induced conformational changes in PIEZO1. Nature. 2019; 573: 230-4.

65. Moroni M, Servin-Vences MR, Fleischer R, Sanchez-Carranza O, Lewin GR. Voltage gating of mechanosensitive PIEZO channels. Nat Commun. 2018; 9: 1096 .

66. Gaub BM, Müller DJ. Mechanical Stimulation of Piezo1 Receptors Depends on Extracellular Matrix Proteins and Directionality of Force. Nano Letters. 2017; 17: 2064-72.

67. Haselwandter CA, MacKinnon R. Piezo's membrane footprint and its contribution to mechanosensitivity. Elife. 2018; 7.

68. Li W, Yu X, Xie F, Zhang B, Shao S, Geng C, et al. A Membrane-Bound Biosensor Visualizes Shear Stress-Induced Inhomogeneous Alteration of Cell Membrane Tension. iScience. 2018; 7: 180-90.

69. Lewis AH, Grandl J. Mechanical sensitivity of Piezo1 ion channels can be tuned by cellular membrane tension. Elife. 2015; 4.

70. Cox CD, Bae C, Ziegler L, Hartley S, Nikolova-Krstevski V, Rohde PR, et al. Removal of the mechanoprotective influence of the cytoskeleton reveals PIEZO1 is gated by bilayer tension. Nat Commun. 2016; 7: 10366.

71. De Vecchis D, Beech DJ, Kalli AC. Molecular dynamics simulations of Piezo1 channel opening by increases in membrane tension. Biophys J. 2021.

72. Shi J, Hyman AJ, De Vecchis D, Chong J, Lichtenstein L, Futers TS, et al. Sphingomyelinase Disables Inactivation in Endogenous PIEZO1 Channels. Cell Rep. 2020; 33: 108225.

73. Scheuring $M$, Yi-Chih Lin How Piezo proteins work weillcornelledu/news/2019/08. 2019.

74. Wang Y, Chi S, Guo H, Li G, Wang L, Zhao Q, et al. A lever-like transduction pathway for long-distance chemical- and mechano-gating of the mechanosensitive Piezo1 channel. Nat Commun. 2018; 9: 1300.

75. Solis AG, Bielecki P, Steach HR, Sharma L, Harman CCD, Yun S, et al Mechanosensation of cyclical force by PIEZO1 is essential for innate immunity. Nature. 2019; 573: 69-74.

76. Siragusa M, Oliveira Justo AF, Malacarne PF, Strano A, Buch A, Withers B, et al. VE-PTP inhibition elicits eNOS phosphorylation to blunt endothelial dysfunction and hypertension in diabetes. Cardiovasc Res. 2021; 117: 1546-56.

77. Stewart L, Turner NA. Channelling the Force to Reprogram the Matrix: Mechanosensitive Ion Channels in Cardiac Fibroblasts. Cells. 2021; 10

78. Beech DJ. Endothelial Piezo1 channels as sensors of exercise. J Physiol. 2018; 596: 979-84.

79. Ranade SS, Qiu Z, Woo SH, Hur SS, Murthy SE, Cahalan SM, et al. Piezo1, a mechanically activated ion channel, is required for vascular development in mice. Proc Natl Acad Sci U S A. 2014; 111: 10347-52.

80. Faucherre A, Moha Ou Maati H, Nasr N, Pinard A, Theron A, Odelin G, et al. Piezo1 is required for outflow tract and aortic valve development. Journal of molecular and cellular cardiology. 2020; 143: 51-62.

81. Datkhaeva I, Arboleda VA, Senaratne TN, Nikpour G, Meyerson C, Geng Y, et al. Identification of novel PIEZO1 variants using prenatal exome sequencing and correlation to ultrasound and autopsy findings of recurrent hydrops fetalis. Am J Med Genet A. 2018; 176: 2829-34.

82. Li J, Hou B, Beech DJ. Endothelial Piezo1: life depends on it. Channels (Austin). 2015; 9: 1-2.

83. Ridone P, Vassalli M, Martinac B. Piezo1 mechanosensitive channels: what are they and why are they important. Biophys Rev. 2019; 11: 795-805.

84. Hirano K, Tsuchiya M, Takabayashi S, Nagao K, Kitajima Y, Ono Y, et al. 2021.

85. Wu J, Lewis AH, Grandl J. Touch, Tension, and Transduction - The Function and Regulation of Piezo Ion Channels. Trends Biochem Sci. 2017; 42: 57-71.

86. Li C, Rezania S, Kammerer S, Sokolowski A, Devaney T, Gorischek A, et al. Piezo1 forms mechanosensitive ion channels in the human MCF-7 breast cancer cell line. Sci Rep. 2015; 5: 8364.

87. Murthy SE, Dubin AE, Patapoutian A. Piezos thrive under pressure: mechanically activated ion channels in health and disease. Nat Rev Mol Cell Biol. 2017; 18: 771-83.

88. Libby P, Buring JE, Badimon L, Hansson GK, Deanfield J, Bittencourt MS, et al. Atherosclerosis. Nat Rev Dis Primers. 2019; 5: 56.
89. Libby P. Inflammation in atherosclerosis. Nature. 2002; 420: 868-74.

90. Libby P, Ridker PM, Hansson GK, Leducq Transatlantic Network on A. Inflammation in atherosclerosis: from pathophysiology to practice. J Am Coll Cardiol. 2009; 54: 2129-38.

91. Libby P, Loscalzo J, Ridker PM, Farkouh ME, Hsue PY, Fuster V, et al. Inflammation, Immunity, and Infection in Atherothrombosis: JACC Review Topic of the Week. J Am Coll Cardiol. 2018; 72: 2071-81.

92. Libby P, Hansson GK. Inflammation and immunity in diseases of the arterial tree: players and layers. Circ Res. 2015; 116: 307-11.

93. Liu CSC, Ganguly D. Mechanical Cues for T Cell Activation: Role of Piezo1 Mechanosensors. Crit Rev Immunol. 2019; 39: 15-38.

94. Sun Y, Leng P, Song M, Li D, Guo P, Xu X, et al. Piezo1 activates the NLRP3 inflammasome in nucleus pulposus cell-mediated by $\mathrm{Ca}(2+)$ /NF-kappaB pathway. Int Immunopharmacol. 2020; 85: 106681.

95. Albarran-Juarez J, Iring A, Wang S, Joseph S, Grimm M, Strilic B, et al. Piezo1 and Gq/G11 promote endothelial inflammation depending on flow pattern and integrin activation. J Exp Med. 2018; 215: 2655-72.

96. Zhao C, Sun $\mathrm{Q}$, Tang $\mathrm{L}$, Cao $\mathrm{Y}$, Nourse JL, Pathak MM, et al. Mechanosensitive Ion Channel Piezo1 Regulates Diet-Induced Adipose Inflammation and Systemic Insulin Resistance. Front Endocrinol (Lausanne). 2019; 10: 373

97. Aykut B, Chen R, Kim JI, Wu D, Shadaloey SAA, Abengozar R, et al. Targeting Piezo1 unleashes innate immunity against cancer and infectious disease. Sci Immunol. 2020; 5.

98. Gudipaty SA, Lindblom J, Loftus PD, Redd MJ, Edes K, Davey CF, et al. Mechanical stretch triggers rapid epithelial cell division through Piezo1. Nature. 2017; 543: 118-21.

99. Vig M, Kinet JP. Calcium signaling in immune cells. Nat Immunol. 2009; 10: 21-7.

100. Feske S. Calcium signalling in lymphocyte activation and disease. Nat Rev Immunol. 2007; 7: 690-702.

101. Trebak M, Kinet J-P. Calcium signalling in T cells. Nature Reviews Immunology. 2019; 19: 154-69.

102. Romac JM, Shahid RA, Swain SM, Vigna SR, Liddle RA. Piezo1 is a mechanically activated ion channel and mediates pressure induced pancreatitis. Nat Commun. 2018; 9: 1715.

103. Walmsley SR. Pressure regulate immune cell function Nature. 2019.

104. Williams ER. PIEZO1 promotes inflammation. 2019; 12: eaaz4154.

105. Zhang C, Zhou T, Chen Z, Yan M, Li B, Lv H, et al. Coupling of Integrin alpha5 to Annexin A2 by Flow Drives Endothelial Activation. Circ Res. 2020; $127:$ 1074-90.

106. Demos C, Williams D, Jo H. Disturbed Flow Induces Atherosclerosis by Annexin A2-Mediated Integrin Activation. Circ Res. 2020; 127: 1091-3.

107. Mantella LE, Quan A, Verma S. Variability in vascular smooth muscle cell stretch-induced responses in 2D culture. Vasc Cell. 2015; 7: 7.

108. Jufri NF, Mohamedali A, Avolio A, Baker MS. Mechanical stretch: physiological and pathological implications for human vascular endothelial cells. Vasc Cell. 2015; 7: 8.

109. Han Y, Huang K, Yao Q-P, Jiang Z-L. Mechanobiology in vascular remodeling. National Science Review. 2018; 5: 933-46.

110. Retailleau K, Duprat F, Arhatte M, Ranade SS, Peyronnet R, Martins JR, et al. Piezo1 in Smooth Muscle Cells Is Involved in Hypertension-Dependent Arterial Remodeling. Cell Rep. 2015; 13: 1161-71.

111. Shinge SAU, Zhang D, Achu Muluh T, Nie Y, Yu F. Mechanosensitive Piezo1 Channel Evoked-Mechanical Signals in Atherosclerosis. Journal of Inflammation Research. 2021; Volume 14: 3621-36.

112. Rosenfeld ME. Macrophage proliferation in atherosclerosis: an historical perspective. Arterioscler Thromb Vasc Biol. 2014; 34: e21-2.

113. Randolph GJ. Proliferating macrophages prevail in atherosclerosis. Nature medicine. 2013; 19: 1094-5.

114. Randolph GJ. Mechanisms that regulate macrophage burden in atherosclerosis. Circ Res. 2014; 114: 1757-71.

115. Bennett MR, Sinha S, Owens GK. Vascular Smooth Muscle Cells in Atherosclerosis. Circ Res. 2016; 118: 692-702.

116. Basatemur GL, Jorgensen HF, Clarke MCH, Bennett MR, Mallat Z. Vascular smooth muscle cells in atherosclerosis. Nat Rev Cardiol. 2019; 16: 727-44.

117. Deivasikamani V, Dhayalan S, Abudushalamu Y, Mughal R, Visnagri A, Cuthbertson $\mathrm{K}$, et al. Piezo1 channel activation mimics high glucose as a stimulator of insulin release. Sci Rep. 2019; 9: 16876.

118. Wang L, You X, Lotinun S, Zhang L, Wu N, Zou W. Mechanical sensing protein PIEZO1 regulates bone homeostasis via osteoblast-osteoclast crosstalk. Nat Commun. 2020; 11: 282.

119. Miyamoto T, Mochizuki T, Nakagomi H, Kira S, Watanabe M, Takayama $Y$, et al. Functional role for Piezo1 in stretch-evoked $\mathrm{Ca}(2)(+)$ influx and ATP release in urothelial cell cultures. J Biol Chem. 2014; 289: 16565-75. 
120. Pathak MM, Nourse JL, Tran T, Hwe J, Arulmoli J, Le DT, et al. Stretch-activated ion channel Piezo1 directs lineage choice in human neural stem cells. Proc Natl Acad Sci U S A. 2014; 111: 16148-53.

121. Lhomme A, Gilbert G, Pele T, Deweirdt J, Henrion D, Baudrimont I, et al. Stretch-activated Piezo1 Channel in Endothelial Cells Relaxes Mouse Intrapulmonary Arteries. Am J Respir Cell Mol Biol. 2019; 60: 650-8.

122. Chahine MN, Dibrov E, Blackwood DP, Pierce GN. Oxidized LDL enhances stretch-induced smooth muscle cell proliferation through alterations in nuclear protein import. Can J Physiol Pharmacol. 2012; 90: 1559-68.

123. Liu S, Li Y, Zhang Z, Xie F, Xu Q, Huang X, et al. alpha1-Adrenergic receptors mediate combined signals initiated by mechanical stretch stress and norepinephrine leading to accelerated mouse vein graft atherosclerosis. J Vasc Surg. 2013; 57: 1645-56, 56 e1-3.

124. Qi YX, Yao QP, Huang K, Shi Q, Zhang P, Wang GL, et al. Nuclear envelope proteins modulate proliferation of vascular smooth muscle cells during cyclic stretch application. Proc Natl Acad Sci U S A. 2016; 113: 5293-8.

125. Chen J, Zhou Y, Liu S, Li C. Biomechanical signal communication in vascular smooth muscle cells. J Cell Commun Signal. 2020; 14: 357-76.

126. Caolo V, Debant M, Endesh N, Futers TS, Lichtenstein L, Bartoli F, et al. Shear stress activates ADAM10 sheddase to regulate Notch1 via the Piezo1 force sensor in endothelial cells. Elife. 2020; 9.

127. Maneshi MM, Ziegler L, Sachs F, Hua SZ, Gottlieb PA. Enantiomeric Abeta peptides inhibit the fluid shear stress response of PIEZO1. Sci Rep. 2018; 8: 14267.

128. Qiu J, Zheng Y, Hu J, Liao D, Gregersen H, Deng X, et al. Biomechanical regulation of vascular smooth muscle cell functions: from in vitro to in vivo understanding. J R Soc Interface. 2014; 11: 20130852.

129. Liu G, Hitomi H, Hosomi N, Lei B, Nakano D, Deguchi K, et al. Mechanical stretch augments insulin-induced vascular smooth muscle cell proliferation by insulin-like growth factor-1 receptor. Exp Cell Res. 2011; 317: 2420-8

130. Gordon E, Schimmel L, Frye M. The Importance of Mechanical Forces for in vitro Endothelial Cell Biology. Front Physiol. 2020; 11: 684.

131. Sugisawa E, Takayama Y, Takemura N, Kondo T, Hatakeyama S, Kumagai $Y$, et al. RNA Sensing by Gut Piezo1 Is Essential for Systemic Serotonin Synthesis. Cell. 2020; 182: 609-24 e21.

132. Maruyama K, Nemoto E, Yamada S. Mechanical regulation of macrophage function - cyclic tensile force inhibits NLRP3 inflammasome-dependent IL-1beta secretion in murine macrophages. Inflamm Regen. 2019; 39:3.

133. Newby AC. Matrix metalloproteinases regulate migration, proliferation, and death of vascular smooth muscle cells by degrading matrix and non-matrix substrates. Cardiovasc Res. 2006; 69: 614-24.

134. Chen Y, Waqar AB, Nishijima K, Ning B, Kitajima S, Matsuhisa F, et al. Macrophage-derived MMP-9 enhances the progression of atherosclerotic lesions and vascular calcification in transgenic rabbits. J Cell Mol Med. 2020; 24: 4261-74.

135. Olejarz W, Lacheta D, Kubiak-Tomaszewska G. Matrix Metalloproteinases as Biomarkers of Atherosclerotic Plaque Instability. Int J Mol Sci. 2020; 21.

136. Kogo T, Hiro T, Kitano D, Takayama T, Fukamachi D, Morikawa T, et al. Macrophage accumulation within coronary arterial wall in diabetic patients with acute coronary syndrome: a study with in-vivo intravascular imaging modalities. Cardiovasc Diabetol. 2020; 19: 135.

137. Xu H, Jiang J, Chen W, Li W, Chen Z. Vascular Macrophages in Atherosclerosis. J Immunol Res. 2019; 2019: 4354786.

138. Robbins CS, Hilgendorf I, Weber GF, Theurl I, Iwamoto Y, Figueiredo JL, et al. Local proliferation dominates lesional macrophage accumulation in atherosclerosis. Nat Med. 2013; 19: 1166-72.

139. Milutinovic A, Suput D, Zorc-Pleskovic R. Pathogenesis of atherosclerosis in the tunica intima, media, and adventitia of coronary arteries: An updated review. Bosn J Basic Med Sci. 2020; 20: 21-30.

140. Bacakova L, Travnickova M, Filova E, Matějka R, Stepanovska J, Musilkova J, et al. The Role of Vascular Smooth Muscle Cells in the Physiology and Pathophysiology of Blood Vessels. Muscle Cell and Tissue - Current Status of Research Field; 2018.

141. Mousawi F, Peng H, Li J, Ponnambalam S, Roger S, Zhao H, et al. Chemical activation of the Piezo1 channel drives mesenchymal stem cell migration via inducing ATP release and activation of P2 receptor purinergic signaling. Stem Cells. 2020; 38: 410-21.

142. Zhang T, Chi S, Jiang F, Zhao Q, Xiao B. A protein interaction mechanism for suppressing the mechanosensitive Piezo channels. Nature Communications. 2017; 8: 1797.

143. Kuntze A, Goetsch O, Fels B, Najder K, Unger A, Wilhelmi M, et al. Protonation of Piezo1 Impairs Cell-Matrix Interactions of Pancreatic Stellate Cells. Front Physiol. 2020; 11: 89.
144. Holt J, Zeng W-Z, Evans E, Woo S-H, Ma S, Abuwarda H, et al. Spatiotemporal dynamics of PIEZO1 localization controls keratinocyte migration during wound healing. bioRxiv; 2020.

145. Onoue N, Nawata J, Tada T, Zhulanqiqige D, Wang H, Sugimura K, et al. Increased static pressure promotes migration of vascular smooth muscle cells: involvement of the Rho-kinase pathway. Journal of cardiovascular pharmacology. 2008; 51: 55-61.

146. Sit B, Feng Z, Xanthis I, Marhuenda E, Zingaro S, Shanahan C, et al. 2020.

147. Kim NY, Kohn JC, Huynh J, Carey SP, Mason BN, Vouyouka AG, et al. Biophysical induction of vascular smooth muscle cell podosomes. PLoS One. 2015; 10: e0119008.

148. Hope JM, Lopez-Cavestany M, Wang W, Reinhart-King CA, King MR. Activation of Piezo1 sensitizes cells to TRAIL-mediated apoptosis through mitochondrial outer membrane permeability. Cell Death Dis. 2019; 10: 837.

149. Desouza M, Gunning PW, Stehn JR. The actin cytoskeleton as a sensor and mediator of apoptosis. Bioarchitecture. 2012; 2: 75-87.

150. Goldblatt ZE, Cirka HA, Billiar KL. Mechanical Regulation of Apoptosis in the Cardiovascular System. Ann Biomed Eng. 2021; 49: 75-97.

151. Guha S, Cullen JP, Morrow D, Colombo A, Lally C, Walls D, et al. Glycogen synthase kinase 3 beta positively regulates Notch signaling in vascular smooth muscle cells: role in cell proliferation and survival. Basic Res Cardiol. 2011; 106: 773-85.

152. Ahmed S, Warren DT. Vascular smooth muscle cell contractile function and mechanotransduction. Vessel Plus. 2018; 2.

153. Liang GP, Xu J, Cao LL, Zeng YH, Chen BX, Yang J, et al. Piezo1 induced apoptosis of type II pneumocytes during ARDS. Respir Res. 2019; 20: 118.

154. Jiang L, Zhao YD, Chen WX. The Function of the Novel Mechanical Activated Ion Channel Piezo1 in the Human Osteosarcoma Cells. Med Sci Monit. 2017; 23: 5070-82.

155. Liang J, Huang B, Yuan G, Chen Y, Liang F, Zeng H, et al. Stretch-activated channel Piezo1 is up-regulated in failure heart and cardiomyocyte stimulated by AngII. Am J Transl Res. 2017; 9: 2945-55.

156. Jiang F, Yin K, Wu K, Zhang M, Wang S, Cheng H, et al. The mechanosensitive Piezo1 channel mediates heart mechano-chemo transduction. Nat Commun. 2021; 12: 869.

157. Blythe NM, Muraki K, Ludlow MJ, Stylianidis V, Gilbert HTJ, Evans EL, et al. Mechanically activated Piezo1 channels of cardiac fibroblasts stimulate p38 mitogen-activated protein kinase activity and interleukin-6 secretion. J Biol Chem. 2019; 294: 17395-408.

158. Qian1† TH, Xiao Ma3, Michele Silvestro2, Cristobal F. Rivera 2, Apratim Bajpai1, Zijing Zhang1, Hengdong Qu2, Annanina Corsica2, Bradley Miscovich2, Berk Aykut4, George Miller4,5, Bhama Ramkhelawon2,5*, Weiqiang

Microskeletal_stiffness_promotes_aortic_aneurysm_b.pdf>. 2020

159. Douguet D, Patel A, Xu A, Vanhoutte PM, Honoré E. Piezo Ion Channels in Cardiovascular Mechanobiology. Trends in Pharmacological Sciences. 2019; 40: 956-70.

160. Fermo E, Vercellati C, Marcello AP, Zaninoni A, van Wijk R, Mirra N, et al. Hereditary Xerocytosis due to Mutations in PIEZO1 Gene Associated with Heterozygous Pyruvate Kinase Deficiency and Beta-Thalassemia Trait in Two Unrelated Families. Case Rep Hematol. 2017; 2017: 2769570.

161. Ilkan Z, Wright JR, Goodall AH, Gibbins JM, Jones CI, Mahaut-Smith MP. Evidence for shear-mediated $\mathrm{Ca}(2+)$ entry through mechanosensitive cation channels in human platelets and a megakaryocytic cell line. J Biol Chem. 2017; 292: 9204-17.

162. Leiva O, Leon C, Kah Ng S, Mangin P, Gachet C, Ravid K. The role of extracellular matrix stiffness in megakaryocyte and platelet development and function. Am J Hematol. 2017; 93: 430-41.

163. Zeng WZ, Marshall KL, Min S, Daou I, Chapleau MW, Abboud FM, et al. PIEZOs mediate neuronal sensing of blood pressure and the baroreceptor reflex. Science. 2018; 362: 464-7.

164. Liu CSC, Raychaudhuri D, Paul B, Chakrabarty Y, Ghosh AR, Rahaman O, et al. Cutting Edge: Piezo1 Mechanosensors Optimize Human T Cell Activation. J Immunol. 2018; 200: 1255-60.

165. Syeda R, Xu J, Dubin AE, Coste B, Mathur J, Huynh T, et al. Chemical activation of the mechanotransduction channel Piezo1. Elife. 2015; 4.

166. Botello-Smith WM, Jiang W, Zhang H, Ozkan AD, Lin YC, Pham CN, et al. A mechanism for the activation of the mechanosensitive Piezo1 channel by the small molecule Yoda1. Nat Commun. 2019; 10: 4503.

167. Coste B, Murthy SE, Mathur J, Schmidt M, Mechioukhi Y, Delmas P, et al. Piezo1 ion channel pore properties are dictated by C-terminal region. Nat Commun. 2015; 6: 7223.

168. Bae C, Sachs F, Gottlieb PA. The mechanosensitive ion channel Piezo1 is inhibited by the peptide GsMTx4. Biochemistry. 2011; 50: 6295-300.

169. Beqja D, Haidar S, Nikolaev M, Shen Y, Denholm B. Transgenic Tarantula Toxin: A novel tool to study mechanosensitive ion channels in Drosophila. Journal of insect physiology. 2020; 127: 104116. 
170. Gnanasambandam R, Ghatak C, Yasmann A, Nishizawa K, Sachs F, Ladokhin AS, et al. GsMTx4: Mechanism of Inhibiting Mechanosensitive Ion Channels. Biophys J. 2017; 112: 31-45.

171. Suchyna TM. Piezo channels and GsMTx4: Two milestones in our understanding of excitatory mechanosensitive channels and their role in pathology. Prog Biophys Mol Biol. 2017; 130: 244-53.

172. Evans EL, Cuthbertson K, Endesh N, Rode B, Blythe NM, Hyman AJ, et al. Yoda1 analogue (Dooku1) which antagonizes Yoda1-evoked activation of Piezo1 and aortic relaxation. Br J Pharmacol. 2018; 175: 1744-59.

173. Liu S, Pan X, Cheng W, Deng B, He Y, Zhang L, et al. Tubeimoside I Antagonizes Yoda1-Evoked Piezo1 Channel Activation. Front Pharmacol. 2020; 11: 768

174. Qu S, Li S, Hu Z. Upregulation of Piezo1 Is a Novel Prognostic Indicator in Glioma Patients. Cancer Manag Res. 2020; 12: 3527-36.

175. Zhou W, Liu X, van Wijnbergen JWM, Yuan L, Liu Y, Zhang C, et al. Identification of PIEZO1 as a potential prognostic marker in gliomas. Sci Rep. 2020; 10: 16121.

176. Chan DD, Van Dyke WS, Bahls M, Connell SD, Critser P, Kelleher JE, et al. Mechanostasis in apoptosis and medicine. Progress in Biophysics and Molecular Biology. 2011; 106: 517-24.

177. Pan Y, Yoon S, Sun J, Huang Z, Lee C, Allen M, et al. Mechanogenetics for the remote and noninvasive control of cancer immunotherapy. Proc Natl Acad Sci U S A. 2018; 115: 992-7.

178. Zhang X, Kim TH, Thauland TJ, Li H, Majedi FS, Ly C, et al. Unraveling the mechanobiology of immune cells. Curr Opin Biotechnol. 2020; 66: 236-45.

179. Della Pietra A, Mikhailov N, Giniatullin R. The Emerging Role of Mechanosensitive Piezo Channels in Migraine Pain. Int J Mol Sci. 2020; 21.

180. Romero LO, Massey AE, Mata-Daboin AD, Sierra-Valdez FJ, Chauhan SC, Cordero-Morales JF, et al. Dietary fatty acids fine-tune Piezo1 mechanical response. Nat Commun. 2019; 10: 1200.

181. Ridone P, Vassalli M, Martinac B. Piezo1 mechanosensitive channels: what are they and why are they important. Biophysical Reviews. 2019; 11: 795-805.

182. Yoneda M, Suzuki H, Hatano N, Nakano S, Muraki Y, Miyazawa K, et al. PIEZO1 and TRPV4, which Are Distinct Mechano-Sensors in the Osteoblastic MC3T3-E1 Cells, Modify Cell-Proliferation. Int J Mol Sci. 2019; 20.

183. Michalick L, Kuebler WM. TRPV4-A Missing Link Between Mechanosensation and Immunity. Front Immunol. 2020; 11: 413.

184. Gorelick F, Nathanson MH. TRPV4 helps Piezo1 put the squeeze on pancreatic acinar cells. The Journal of Clinical Investigation. 2020; 130: 2199-201.

185. Shoajei S, Tafazzoli-Shahdpour M, Shokrgozar MA, Haghighipour N. Alteration of human umbilical vein endothelial cell gene expression in different biomechanical environments. Cell Biol Int. 2014; 38: 577-81.

186. Cevallos M, Riha GM, Wang X, Yang H, Yan S, Li M, et al. Cyclic strain induces expression of specific smooth muscle cell markers in human endothelial cells. Differentiation. 2006; 74: 552-61. 